\title{
Bond behavior in NSM-strengthened masonry
}

\section{Hamid Maljaee ${ }^{1}$, Bahman Ghiassi², Paulo B. Lourenço ${ }^{3}$}

4 ABSTRACT

5 Near Surface Mounted (NSM) reinforcement is an interesting technique for seismic strengthening

6 of masonry and historical structures. Despite having several advantages compared to conventional

7 techniques, little attention has been given to understanding the involved mechanisms (such as bond

8 behavior) in the performance of masonry components strengthened with this reinforcement

9 technique. This study presents an experimental and analytical investigation on the bond

10 performance of NSM-strengthened masonry bricks aiming at filling the existing gaps in the

11 available experimental results in the literature. The main focus is on the effect of test setup and

12 bond length, but attention has also been given to the groove size and loading regime effect on the

13 bond performance. The accuracy of the existing bond strength prediction models is also assessed

14 and the required modifications are proposed.

15 Keywords: Near Surface Mounted; Masonry; Strengthening; Bond; FRP; Experimental testing; 16 Analytical modeling.

${ }^{1} \mathrm{PhD}$ Student, ISISE, University of Minho, Department of Civil Engineering, Azurém, 4800-058 Guimarães,

Portugal. Phone: +351 253510 499, fax: +351 253510 217, E-mail: h.maljaee.civil@gmail.com

${ }^{2}$ Marie Curie IF Research Associate, Current address: Microlab, Department of Civil Engineering and Geosciences, TU Delft, Delft, The Netherlands. Phone: +31 15 2788741, E-mail: bahmanghiassi@gmail.com

${ }^{3}$ Professor, ISISE, University of Minho, Department of Civil Engineering, Azurém, 4800-058 Guimarães, Portugal. Phone: +351 253510 209, fax: +351253 510 217, E-mail: pbl@civil.uminho.pt 


\section{$1 \quad 1 \quad$ Introduction}

2 Fiber reinforced polymers (FRP) have been extensively used for strengthening of masonry and

3 concrete structures due to advantages such as low weight, ease of application, corrosion resistance

4 and high durability. These composites are generally used for Externally Bonded Reinforcement

5 (EBR) or Near-Surface Mounted (NSM) strengthening techniques. The disadvantages related to

6 the EBR strengthening techniques (such as special requirement for surface treatment and

7 susceptibility to aggressive environmental conditions), promotes the use of NSM technique.

8 Additionally, the NSM reinforcement does not change the aesthetics of the structure which is a

9 great concern when dealing with restoration of historical structures [1,2]. NSM systems are also

10 more efficient due to their larger bonded area to cross section ratio in comparison with EBR

11 systems. The available literature on strengthening of masonry structures using NSM technique

12 have shown its notable effect on increasing the ductility and capacity of the structures [3]. Despite

13 these advantages, the available literature on characterization and performance assessment of NSM-

14 strengthened masonry is still limited, see e.g. [3-6].

15 The NSM technique involves introducing FRP laminates or bars into slits prefabricated on the

16 tensile face of structural elements using an epoxy adhesive [7]. In these systems, the stresses are

17 transferred from the substrate to the reinforcing material through the adhesive and the interfacial

18 stresses. The adhesive-to-substrate and the FRP-to-adhesive bond performance are therefore

19 critical mechanisms. Although the bond performance has been subject of several studies in case of

20 NSM-strengthened concrete elements, see e.g. [8-15], little attention has been given to

21 strengthened masonry components, see e.g. [2,16-18]. The effect of different parameters

22 (including the dimensions and shape, the adhesive type, the mechanical strength of substrate, the

23 groove dimensions and the bonded length have been deeply investigated in NSM-strengthened 
1 concrete components $[1,2,8,19,20]$. The available studies on NSM-strengthened masonry, has not

2 yet fully covered all these parameters and is mostly devoted to the effect of bond length on limited

3 types of substrate. The majority of available studies are devoted to large bonded lengths and the

4 bond performance in short bonded lengths still remains unexplored.

5 This paper presents an experimental assessment of the bond performance in CFRP NSM-

6 strengthened bricks with special attention to short bonded lengths to fulfill the current gap in the

7 literature. Attention has also been given to the effect of test setup, groove dimensions and loading

8 regime. Based on the produced experimental results and the available data in the literature, a survey

9 is also performed on accuracy of the existing bond strength analytical models and suitable

10 modifications are proposed.

\section{$11 \quad 2$ Experimental program}

\section{$12 \quad 2.1 \quad$ Specimens}

13 The specimens were composed of solid clay bricks with dimensions of $200 \mathrm{~mm} \times 100 \mathrm{~mm} \times 50 \mathrm{~mm}$

14 strengthened with $\mathrm{S} \& \mathrm{P}^{\circledast}$ CFRP strips made of unidirectional carbon fibers. The strips had $10 \mathrm{~mm}$

15 width and $1.4 \mathrm{~mm}$ nominal thickness. A two-part epoxy adhesive (S\&P resin 220) was used to

16 bond the CFRP strips to the bricks following the near surface mounted (NSM) strengthening

17 technique.

18 For preparation of the specimens, rectangular grooves were initially cut on the bricks' surfaces by

19 an electrical saw with the desired width and depth. Then the bricks were washed, cleaned and dried

20 in an oven for 24 hours at $100^{\circ} \mathrm{C}$. After cooling in the laboratory environment, the dust was

21 removed from the grooves using an air compressor. The grooves were then filled with the epoxy

22 up to half of its depth. The CFRP laminates were then carefully inserted into the grooves and were

23 covered with another layer of epoxy. The position of the laminate inside the groove was controlled 
1 by wrapping a tape around the laminate at both ends (outside of the bond area). The tapes also

2 acted as a barrier to prevent penetration of the adhesive out of the bond zone, see Fig 1 . The exterior

3 surface of the tape was greased with oil to minimize the friction with the groove's perimeter during

4 the tests.

5 The laminates were applied with different bond lengths (from $30 \mathrm{~mm}$ to $150 \mathrm{~mm}$ ). A $40 \mathrm{~mm}$

6 unbonded length was left at the loaded end to avoid compressive crushing of the bricks during the

7 tests due to the edge effects, see Fig 2. Two aluminum plates were glued at the end of the laminate

8 to facilitate gripping of the specimens during the tests. The specimens were cured in laboratory

9 conditions for two weeks as suggested in the technical datasheets provided by the manufacturer.

10 The specimens are labeled according to the groove width $(\mathrm{G})$ and bond length (B), throughout the

11 paper.

$12 \quad 2.2 \quad$ Material properties

13 The compressive strength of the bricks was experimentally obtained as $16.7 \mathrm{MPa}$. The tests were

14 performed on $40 \mathrm{~mm} \times 40 \mathrm{~mm} \times 40 \mathrm{~mm}$ cubes following the instructions given in ASTM C67 [21]

15 and EN 772-1 [22]. The tests were conducted under force-controlled conditions at the rate of

$16150 \mathrm{~N} / \mathrm{min}$. To reduce friction, a pair of free-friction Teflon papers (with oil in the middle) was

17 placed between the specimens and the compression plate. Application of the correction factor

18 proposed in ASTM C39/C39M [23] to consider the specific dimensions of the specimens (factor

19 of 0.87 for a height-to-length ratio of 1) lead to a compressive strength of $14.5 \mathrm{MPa}$ as presented

20 in Table 1.

21 The epoxy adhesive had a 14 days tensile strength and elastic modulus of $22 \mathrm{MPa}$ and $7.15 \mathrm{GPa}$,

22 and the CFRP laminate had an elastic modulus of $165 \mathrm{GPa}$, respectively according to [24]. The

23 summary of the materials' mechanical properties is presented in Table 1. 


\section{$1 \quad 2.3 \quad$ Test setup}

2 As no standard test method is available for investigating the bond behavior in NSM-strengthened

3 concrete or masonry specimens, various test setups have been employed by different researchers.

4 A single-lap shear test scheme, by fixing the specimens to a supporting frame from the bottom and

5 pulling the laminate from the top, is often used for this purpose. The specimens are fixed using a

6 rigid restraining plate placed on top of the specimens which, after initial adjustments, is anchored

7 to the supporting frame from the bottom. This leads to application of a pre-compression load to

8 the specimens before starting the tests which can influence the experimental results [5]. Regardless

9 of the advantages and disadvantages of this test setup, the specific geometry and size of the

10 specimens did not allow to use such a system for performing the tests in this study.

11 The single-lap shear bond test setup developed in $[25,26]$ for characterization of the bond behavior

12 in EBR-strengthened bricks was thus used here, see Fig 2. This test setup was not directly

13 applicable for NSM-strengthened specimens due to the geometrical differences of the specimens

14 compared to the EBR-strengthened specimens. In EBR strengthening technique, the FRP sheet is

15 applied on the substrate's surface, while in NSM technique the laminate is inserted inside the

16 specimen for few millimeters. The clamping and restraining systems were thus changed in two

17 stages to optimize the test setup, see Fig 3. In the original test setup, called Class 1 hereafter, the

18 L-shaped plate used for supporting the specimens from top allowed partial restraining of the

19 specimens. Lateral clamping, consisting of four individual clamps, were also used to avoid rotation

20 of the specimens during the tests. In the second test setup, called Class 2 hereafter, the top

21 supporting plate was modified to allow a full restrain. The clamping system consisted of four

22 individual clamps and a free end restraining plate according to the details shown in Fig 3 . Finally,

23 in the third test setup, called Class 3, the full top restraining system (used in Class 2) with an edge 
1 restrain-clamping system were used. The results obtained in each test setup are presented and

2 compared in section 3.2. Based on the obtained results, the best test setup was chosen to investigate

3 the effect of different parameters on the bond performance in NSM-strengthened bricks.

4 For performing the tests, the specimens were positioned on a rigid steel frame and restrained 5 carefully from top and firmly clamped to the frame according to the details discussed in the last

6 paragraph, see Fig 2. A servo-hydraulic system with a maximum capacity of $25 \mathrm{kN}$ was used for

7 performing the tests. The tests were driven under displacement controlled conditions with reference

8 to the internal LVDT of the system by pulling the laminates with a velocity of $0.3 \mathrm{~mm} / \mathrm{min}$. The

9 resultant load was measured by the load cell integrated in the testing machine. One LVDT was

10 also placed at the loaded end to measure the relative slip between the laminate and the substrate,

11 see Fig 2.

$12 \quad 2.4 \quad$ Test parameters

13 The test parameters included the bond length, the groove size and the loading conditions (static

14 and cyclic). To investigate the effect of the groove size, two different sizes in combination with

15 different bond lengths of 30, 60 and $90 \mathrm{~mm}$ were considered. The groove sizes were $13 \mathrm{~mm}$

16 (depth) $\times 3 \mathrm{~mm}$ (width) and $15 \mathrm{~mm}$ (depth) $\times 5 \mathrm{~mm}$ (width). Three specimens were prepared for each

17 groove size and bond length in this stage resulting in a total of 18 specimens. After analysis of the

18 results, the larger groove size, which also showed a better bond performance, was selected for 19 preparation of the next set of specimens.

20 Another group of specimens were prepared for investigating the effect of bond length. These

21 specimens were prepared with the groove dimensions of $15 \mathrm{~mm}$ (depth) $\times 5 \mathrm{~mm}$ and bond lengths

22 of 30, 60, 90, 120 and $150 \mathrm{~mm}$. Five specimens were prepared for each bond length resulting in a

23 total of 25 specimens in this stage. 
1 Both of the above mentioned groups of specimens were tested under monotonic displacement-

2 controlled conditions with the rate of $0.3 \mathrm{~mm} / \mathrm{min}$. Three additional specimens with $15 \mathrm{~mm}$

3 (depth) $\times 5 \mathrm{~mm}$ groove size and $150 \mathrm{~mm}$ bond length were also prepared for performing the tests

4 under static cyclic loading regime. These tests were conducted with a constant displacement rate

5 of $0.6 \mathrm{~mm} / \mathrm{min}$. The tests were performed under incremental cyclic displacements (with the

6 internal LVDT as reference), with three consecutive cycles at each displacement level. The tests

7 were continued until occurrence of delamination. The load history and the summary of loading

8 conditions are presented in Fig 4 and Table 2.

\section{$9 \quad 3 \quad$ Experimental results}

\section{$10 \quad 3.1 \quad$ Typical failure modes}

11 Three distinct failure modes were generally identified in the tested specimens as presented in Fig

12 5: (A) flexural splitting of the bricks at the free end; (B) debonding of the laminate from the brick

13 substrate (at the adhesive-to-brick interface) accompanied by diagonal cracks inside the brick and

14 (C) failure at the adhesive-to-brick interface. The effect of different parameters and test conditions

15 on the failure mode of the specimens are discussed in the following sections. The observed failure

16 mode (A) seems not to be realistic and thus, this type of failure is attempted to be avoided through

17 changing the test parameters.

$18 \quad 3.2 \quad$ Effect of test setup

19 The typical force-slip curves and failure modes obtained from each test setup are presented in Fig

20 6. A clear change of failure mode and increase in the bond strength can be observed in the third

21 test setups in comparison to the first one. Most of the partially restrained specimens (class 1 test

22 setup) showed a combination of failure modes A and B. This seems to be due to the eccentricity

23 of the load and the induced flexural stresses on the specimens. Fully restraining of the specimens 
1 in test setup class 2 led to significant increment of the debonding load with the dominant failure

2 modes of B and C. From the experimental results, it was concluded that the occurrence of failure

3 mode B was partly due to the clamping system in these specimens. A different clamping system

4 (full edge restraining) was therefore used in the test setup class 3. This change led to occurrence

5 of adhesive-to-brick interface delamination (with the exception of only two specimens that had

6 failure modes A and B) in the specimens tested in class 3 test setup. Again, significant increment

7 was observed in the delamination force or force-slip curves in the specimens tested in test setup

8 class 3 in comparison with those tested in test setup class 2. This test setup (class 3 ) was therefore

9 chosen for performing the next tests.

$10 \quad 3.3$ Groove size

11 The effect of groove size on the bond behavior has been the subject of several studies in case of

12 NSM-strengthened concrete components $[8,13,27,28]$. In general, it is believed that increment of

13 groove dimensions can lead to decrement of stresses inside the substrate (as the stress transfer area

14 increases). This can lead to increment of failure load if the failure mode remains unchanged (i.e.

15 inside the substrate). In other cases, where the failure mode has changed to adhesive failure, the

16 failure load has shown insignificant changes. These results show that the groove size can be

17 optimized, based on the mechanical properties of the substrate and adhesive, to obtain the

18 maximum bond strength in the reinforced system.

19 In case of NSM-strengthened masonry, the available results on the effect of groove size are still

20 very limited but the mechanisms are expected to be similar to NSM-concrete systems. Among the

21 few available studies, Dizhur et al. [5] investigated the effect of groove dimensions on the bond

22 behavior in NSM-strengthened masonry prisms. They observed that increasing the groove width

23 from $3 \mathrm{~mm}$ to $12 \mathrm{~mm}$ had no influence on the ultimate debonding load as all the specimens failed 
1 by adhesive interfacial debonding. Increasing the depth of the groove, however, led to the change

2 of failure mode to splitting of the brick, but the debonding load remained unchanged.

3 The tests performed in the current study showed a significant influence of the groove size on the

4 debonding load. The variation of the debonding load, $f_{\mathrm{ut}}$, with groove size is presented in Fig 7 for

5 specimens with different bonded lengths. It can be observed that increasing the groove dimensions

6 led to $51 \%, 45 \%$ and $44.5 \%$ increase in debonding force in the specimens with 30,60 and $90 \mathrm{~mm}$

7 bond length, respectively. The effect of groove dimensions is similar in all bonded length. As both

8 the groove depth and width were changed simultaneously, the effect of each parameter cannot be

9 investigated separately. The failure mode (B) was the dominant failure mode in specimens with

10 smaller groove dimensions (G1), while, failure mode (C) was mostly observed in the specimens

11 with larger groove dimensions (G2).

123.4 Bond length

13 The effect of bond length has been extensively investigated in case of NSM-strengthened concrete

14 components $[8,13,27,28]$. In case of NSM-to-masonry, the available results are again limited, see

15 e.g. [29,30], and mostly devoted to bonded lengths in the range of $180 \mathrm{~mm}$ to $560 \mathrm{~mm}[5,18,30])$.

16 A clear understanding of the bond performance in short bonded lengths is missing but critical for

17 masonry components. This is due to the short distance between the mortar joints (usually around

$18100 \mathrm{~mm}$ ) where there is the highest possibility of cracking. The current study is therefore focused

19 on characterization of the bond performance in short bonded lengths (ranging from 30 to $150 \mathrm{~mm}$ ).

20 The influence of bonded length on the force-slip response (envelopes) and the debonding force are

21 presented in Fig 8. The coefficient of variation $(\mathrm{CoV})$ of the results was in the acceptable range of

225 to $10 \%$. The force-slip curves show that the debonding force, $f_{\mathrm{ut}}$, and its corresponding slip,

23 increase with increment of the bonded length as also reported in the literature, see e.g. [1,5]. On 
1 the other hand, it seems that the initial stiffness of the force-slip curves slightly decreases with

2 increment of the bonded length. The changes of the debonding force seem to become insignificant

3 in the specimens with bond lengths longer than $120 \mathrm{~mm}$. This observation shows that the effective

4 bond length, $l_{\mathrm{e}}$, is in the range of $120 \mathrm{~mm}$ to $150 \mathrm{~mm}$ in these specimens. Increment of the bond

5 length also influenced the failure mode in each test setup class. Improvement of the failure mode

6 from mode A to mode B was observed in class 1 set setup with increasing the bond length from

$730 \mathrm{~mm}$ to $90 \mathrm{~mm}$. In the same range of bond length, failure mode $\mathrm{C}$ dominantly occurred in the

8 specimens tested in class 2 setup. In test setup class 3, besides two specimens that failure modes

$9 \mathrm{~A}$ and $\mathrm{B}$ in $30 \mathrm{~mm}$ and $60 \mathrm{~mm}$ bonded length range, most of the specimens had failure mode $\mathrm{C}$ in

10 all bonded lengths. One can track the changes of failure modes in each class of test setup due to

11 variation of bond length in Fig 9.

$12 \quad 3.5 \quad$ Cyclic loading

13 The force-slip response of the specimens tested under quasi-static cyclic loading is illustrated in

14 Fig 10a. The results are presented in comparison with the static tests results. It can be observed

15 that the cyclic loading considered in this study shows insignificant effect on the ultimate debonding

16 load. Although it should be noted that the number of considered cycles in this study are limited

17 and a different behavior maybe observed when larger number of cycles are considered. Different

18 observed behaviors in the specimens may be due to material variability and the different applied

19 load history, see Fig 10a. Therefore, further experiments are required to confirm the effect of cyclic

20 loading on the FRP-brick bond behavior. An in-cycle reduction of strength can, however, be

21 observed in each deformation range. This reduction is more obvious in higher load levels. The in-

22 cycle degradation trend in each cyclic set is illustrated in Fig 10b. A similar trend was also reported

23 in $[17,18]$. 


\section{Existing bond strength predictive models}

2 Numerous models can be found in the literature for predicting the bond strength in NSM-

3 strengthened concrete components [1,10,12,31,32]. Whereas, due to the lack of enough

4 experimental data, few models exist for NSM-strengthened masonry elements $[5,18,30]$. These

5 models, although not always clearly separable, can be generally categorized as (a) empirical

6 models proposed based on regression analysis of experimental data or (b) fracture mechanics based

7 models. Among the available models in the literature, three existing models recently proposed for

8 NSM-masonry elements [18,30] and two existing models proposed for NSM-concrete [10,31] are

9 reviewed in this section. The accuracy of these models in predicting the bond strength in NSM-

10 strengthened masonry is then evaluated in Sec. 5.

114.1 Model proposed by Seracino et al. [10]

12 Seracino et al. [10] proposed a generic model for EBR and NSM-strengthened concrete elements.

13 The model was developed based on equilibrium and compatibility equations of laminate-to-

14 concrete joints with the assumption of a predefined failure plane inside the concrete (cohesive

15 failure mode in the substrate) and a triangular bond-slip law. The model was validated and its

16 parameters were optimized by nonlinear regression analysis of a set of experimental data.

17 Assuming that the local bond-slip law parameters (i.e. maximum shear stress and maximum slip),

18 and the shape of the failure plane have direct influence on the bond strength in NSM-concrete

19 joints, the debonding load, $P_{\max }$, was defined as:

$20 P_{\max }=\sqrt{\tau_{\max } S_{\max }} \sqrt{L_{p e r}(E A)_{p}}$

21 where, $\tau_{\max }$ is the shear bond strength in the bond-slip law, $s_{\max }$ is the slip corresponding to the

$22 \tau_{\max }, L_{\mathrm{per}}$ is the length of the debonding failure plane, $E$ is the laminate's elastic modulus and $A$ is

23 the cross section area of the laminate. $\tau_{\max } \times s_{\max }$ and $L_{\mathrm{per}}$ are defined as: 
$1 \tau_{\max } s_{\max }=0.976 \varphi_{f}^{0.526} f_{c}^{0.6}$

$2 \quad \varphi_{f}=\frac{d_{f}}{b_{f}}$

$3 \quad L_{p e r}=d_{f}+2 b_{f}$

4 where, $f_{c}$ is the cylindrical compressive strength of concrete, and $d_{f}$ and $b_{f}$ are the length of the

5 failure plane perpendicular and parallel to the substrate surface, respectively. Substituting Eqs. (2-

6 4) into Eq. (1), gives:

$7 \quad P_{\max }=0.988 \varphi_{f}^{0.263} f_{c}^{0.3} \sqrt{L_{p e r}(E A)_{p}}$

8 The effective bond length (the length beyond which the maximum debonding resistance can be

9 obtained), $L_{e}$, can be calculated as:

$10 \quad L_{e}=\frac{\pi}{2 \lambda}$

$11 \quad \lambda^{2}=\frac{\tau_{\max } L_{p e r}}{s_{\max }(E A)_{p}}$

12 where, the $\tau_{\max }$ and $s_{\max }$ are obtained based on a statistical analysis as:

$13 \tau_{\max }=\left(0.802+0.078 \varphi_{f}\right) f_{c}^{0.6}$

$14 S_{\max }=\frac{0.976 \varphi_{f}{ }^{0.526}}{0.802+0.078 \varphi_{f}}$

15 It can be observed that $\tau_{\max }$ is a function of compressive strength and $\varphi_{f}$, while $s_{\max }$ is only a

16 function of $\varphi_{f}$ in this model. For obtaining the debonding resistance for bonded lengths less than

17 the effective bond length $\left(L<L_{\mathrm{e}}\right)$, application of a reduction factor $\left(=L<L_{\mathrm{e}}\right)$ according to Eq. (5) is 18 proposed [10]. 
$1 \quad 4.2$ Model proposed by Zhang et al. [31]

2 Zhang et al. [31] used fracture mechanics approach for proposing an analytical formula for bond

3 strength in NSM-concrete systems. In this model the debonding load is obtained as follows:

$4 \quad P_{\max }=\beta_{L} \sqrt{2 G_{f}(E A)_{p} C_{\text {failure }}}$

5 where $G_{f}$ is the interfacial fracture energy, $\beta_{L}$ is a parameter taking into account the effect of bond

6 length, and $C_{\text {failure }}$ is the perimeter of the failure surface which is obtained as the sum of the three

7 side lengths of the groove. Interfacial fracture energy can be obtained as [33]:

$8 G_{f}=0.4 \varphi_{f}^{0.422} f_{c}^{0.619}$

9 where, $\varphi_{f}$ can be obtained from Eq. (3). For the proposed model, the effective bond length is

10 expressed as:

$11 \quad L_{e}=\frac{1.66}{\eta}$

12 where

$13 \quad \eta^{2}=\frac{\tau_{\max } C_{\text {failure }}}{2 G_{f}(E A)_{p}}$

14 and $\tau_{\max }$ was obtained through regression analysis of numerical results, as:

$15 \tau_{\max }=1.15 \varphi_{f}^{0.138} f_{c}^{0.613}$

16 The parameter $\beta_{L}$ is equal to 1 if $L_{\mathrm{b}} \geq L_{\mathrm{e}}$, and can be obtained as follows when $L_{\mathrm{b}}<L_{\mathrm{e}}$ (was obtained

17 as the best fit of experimental results):

$18 \quad \beta_{L}=\frac{L_{b}}{L_{e}}\left(2.08-1.08 \frac{L_{b}}{L_{e}}\right)$

194.3 Model proposed by Willis et al. [31]

20 Willis et al. [30] modified the model proposed by Seracino et al. [10] for application to NSM-

21 masonry systems. They proposed to use the masonry flexural tensile strength, $f_{u t}$, instead of 
1 cylindrical compressive strength in Eq. (5). Substituting the flexural tensile strength, obtained from

2 Eq. (16), into Eq. (5) gives the bond strength as presented in Eq. (17).

$3 \sqrt{f_{c}}=\frac{f_{u t}}{0.53}$

$4 \quad P_{\max }=1.45 \varphi_{f}^{0.263} f_{u t}^{0.6} \sqrt{L_{p e r}(E A)_{p}}$

5 In this model, the authors propose to use the same equations as Eqs. (6-9), for obtaining the

6 effective bond length in NSM-strengthened masonry.

$7 \quad 4.4 \quad$ Model proposed by Kashyap et al. [18]

8 Kashyap et al. [18] proposed two formulas for strengthened masonry components: (1) a generic

9 formula for both EBR and NSM strengthening systems, Eq. (18), and (2) a specific formula for

10 NSM-strengthening systems, Eq. (19):

$11 P_{\text {max }}=1.99 \varphi_{f}^{0.19} f_{u t}^{0.47} \sqrt{L_{p e r}(E A)_{p}}$

$12 P_{\text {max }}=2.63 \varphi_{f}^{-0.12} f_{u t}^{0.47} \sqrt{L_{p e r}(E A)}{ }_{p}$

13 It can be observed that the flexural strength of the masonry is used in both equations for obtaining

14 the bond strength. Moreover, both equations have a similar form with the only difference in the

15 values of the parameters (fitted with experimental data). In this model, Eq. (6) is proposed for

16 obtaining the effective bond length but by using the following formulas for $\tau_{\max }$ and $\mathrm{s}_{\max }$ :

$17 \tau_{\text {max }}=8.83 \varphi_{f}^{0.15} f_{u t}^{0.2}$

$18 s_{\max }=0.45 \varphi_{f}^{0.23} f_{u t}^{0.74}$

19 In contrary to Eqs. (8-9), it can be observed that Kashyap et al. [18] considered that both $\tau_{\max }$ and

$20 s_{\max }$ are dependent on the tensile strength of masonry unit and the aspect ratio of the failure plane $21\left(\varphi_{f}\right)$. 


\section{Assessment of accuracy of existing models}

2 The accuracy of the existing models (presented in the last section) in predicting the maximum

3 debonding force in NSM-strengthened masonry components is evaluated in this section. A

4 database of experimental results on NSM-strengthened masonry components is initially formed.

5 The database consisted of 70 experimental results available in the literature $[2,5,16-18,30]$ and the

6 experimental results produced in the current study, leading to a total of 103 test records. As the

7 existing bond strength models are based on the assumption that failure occurs inside the substrate

8 (cohesive failure), the specimens with sliding or adhesive failure were removed from the database.

9 The final database, therefore, consisted of 89 bond test results in total as presented in Table 3.

10 A comparison is made between the bond strength predictions and the experimental results. The

11 results are presented in Table 4 and Fig 11. The first two models, i.e. Seracino et al. [10] and Zhang

12 et al [31], proposed for concrete elements showed a very low $\mathrm{R}^{2}$ values with respect to the

13 experimental results and thus completely failed to predict the bond strength in NSM-strengthened

14 masonry components, see Fig 11 . On the other hand, the models proposed by Willis et al [30] and

15 Kashyap et al [18] produced better predictions. It seems that the model proposed by Kashyap et

16 al. (NSM) shows the best correlation with the experimental database, with an $\mathrm{R}^{2}$ of 0.85 .

17 Contrarily, the predictions are not reasonable for specimens with short bond lengths ( $1<150 \mathrm{~mm})$,

18 having an $\mathrm{R}^{2}$ ranged between $0.52-0.64$. The model proposed by Willis et al. [30], however, failed

19 to predict the debonding force of specimens with short bond length. This can be due to the

20 overestimation of the effective bond length and the proposed reduction factor in this model. The

21 effective bond length of the specimens tested in the current study was estimated to be in the range

22 of 120 to $150 \mathrm{~mm}$. However, the model proposed by Willis et al. [30] predicts the effective bond

23 length of around $260 \mathrm{~mm} 290 \mathrm{~mm}$, see specimen ID 57-89 in Table 4. This larger effective bond 
1 length in comparison to the experimental results, leads to application of a larger reduction factor

2 and thus underestimation of the bond strength.

\section{$3 \quad 6$ Proposed model}

4 Most available bond strength models for NSM-strengthened masonry systems [18,30], are

5 developed based on modification of the model proposed by Seracino et al. [10]. The flexural tensile

6 strength of the masonry is generally substituted for the cylindrical compressive strength and the

7 other parameters are modified based on the best fit with the available experimental data. Although

8 the predictions were in an acceptable range in the model proposed by Kashyap et al (NSM) [18],

9 Fig 11d, it seems that some improvements can still be done for predicting the bond strength of

10 specimens with short bond lengths. Additionally, the predictions of the effective bond length were

11 not accurate in some cases.

12 For this reason, the fracture mechanics based model proposed by Zhang et al. [31] for NSM-

13 strengthened concrete, is modified for NSM-strengthened masonry components in this section. In

14 this model, the flexural tensile strength of masonry is substituted for the compressive strength in

15 Eqs. (11) and (14) leading to the following expressions (knowing that $\sqrt{f_{c}}=\frac{f_{u t}}{0.53}$ ):

$16 G_{f}=1.424 \varphi_{f}^{0.422} f_{u t}^{1.238}$

$17 \tau_{\max }=4.09 \varphi_{f}^{0.138} f_{u t}^{1.226}$

18 Substituting Eqs. (22-23) in Eqs. (10) and (12), the debonding force and the effective bond length

19 in NSM-strengthened masonry can be obtained. Based on the available experimental database, the

20 parameter $\beta_{L}$, in Eq. (15), is also modified. To this aim, the $L_{b} / L_{e}$ is plotted against $P / P_{\max }$ from the

21 experimental results produced in this study. The best-fitted quadratic equation is then obtained as,

22 see Fig 12: 
$1 \quad \beta_{L}=\frac{L_{b}}{L_{e}}\left(2.36-1.36 \frac{L_{b}}{L_{e}}\right)$

2 The accuracy of the model with the proposed modifications is presented in Fig 13 in comparison

3 with the experimental results. The results obtained using the proposed model is compared with

4 three existing models (specifically proposed for masonry structures) in Table 4. A good agreement

5 with the experimental results is observed over a wide range of bond lengths. The model is able to

6 predict an effective bond length in the specimens tested in the present study with high precision

7 with an average of $188 \mathrm{~mm}$ (close to value estimated based on the experimental results). In

8 addition, the predicted bond strength was improved in specimens with short bond lengths (30-

$9150 \mathrm{~mm}$ ), which are shown with red spots in Fig 13, having $\mathrm{R}^{2}$ of 0.8 . A comparison between the

10 proposed model with other available models for NSM-masonry systems, Table 5, shows this model

11 produces reasonably accurate predictions with an average $P / P_{\max }$ of $1.08(\mathrm{CoV}=23 \%)$.

\section{$\begin{array}{lll}12 & 7 & \text { Conclusions }\end{array}$}

13 An experimental investigation on the bond performance of Near Surface Mounted (NSM)-

14 strengthened bricks was presented in this paper. The effect of test setup and anchorage method on

15 the experimental results were initially investigated and discussed. The focus was then given to the

16 effect of different parameters on the bond behavior including the bond length, groove size and

17 loading conditions. The following conclusions can be drawn from the experimental results:

18 1) The test setup was found to have a significant influence on the failure mode and the debonding

19 force of the specimens. This implies that comparisons with available data in the literature

20 should be done with special care. A new test setup was developed in this study with the

21 advantage, compared to conventional test setups, that no pre-compression load is applied on

22 the specimens before testing. 
1 2) The specimens with larger groove dimensions showed better bond performance in all bonded

2 lengths without any change of failure mode. The presented results are however limited and a 3 more extensive experimental study is still required for drawing conclusive remarks on the $4 \quad$ effect of groove size.

5 3) A significant increase of bond strength was observed in the specimens with increment of the 6 bonded length from $30 \mathrm{~mm}$ to $120 \mathrm{~mm}$ bond length. The specimens with bonded lengths larger 7 than $120 \mathrm{~mm}$ did not show significant change of debonding load implying that the effective 8 bond length is in the range of $120-150 \mathrm{~mm}$ in the specimens tested in this study. Based on the 9 experimental results, a new formula was proposed for modification of the bond strength in 10 short bonded lengths.

11 4) The influence of cyclic loading on the global force-slip behavior was assessed. A slight in12 cycle reduction of force and stiffness was observed in each displacement level after unloading13 reloading. The results show the effect of cyclic loads on the bond performance can be 14 significant and need to be considered at the design stage. The presented results are however 15 limited and a comprehensive experimental program is necessary in future works for drawing 16 clearer conclusions on the cyclic bond response and development of suitable constitutive laws.

17 5) Accuracy of the existing models in predicting the bond strength of a large number of 18 experimental results was also evaluated. The results showed that most of the current strategies 19 fail in accurate prediction of the effective bond length and consequently the bond strength. 20 Based on the experimental results developed in this study, the formulation of the effective bond 21 length was modified and a fracture-based bond strength model was proposed for NSM22 strengthened masonry components. 


\section{Acknowledgements}

2 The second author acknowledges the financial support of the financial support of the European

3 Union's Marie Curie Individual Fellowship program under REA grant agreement No. 701531.

5 References

6 [1] Seracino R, Jones NM, Ali MS, Page MW, Oehlers DJ. Bond strength of Near-Surface $7 \quad$ Mounted FRP strip-to-concrete joints. J Compos Constr 2007;11(4):401-9.

8 [2] Petersen RB, Masia MJ, Seracino R. Bond behavior of Near-Surface Mounted FRP strips 9 bonded to modern clay brick masonry prisms: Influence of strip orientation and 10 compression perpendicular to the strip. J Compos Constr 2009;13(3):169-78.

11 [3] De Lorenzis L, Tinazzi D, Nanni A. Near-Surface Mounted FRP rods for masonry strengthening: Bond and flexural testing. Mecc. delle Strutt. Muratura Rinf. con FRP Mater., 2000.

14 [4] Su Y, Wu C, Griffth MC. Modelling of the bond-slip behavior in FRP reinforced masonry. 15 Constr Build Mater 2011;25(1):328-34.

16 [5] Dizhur D, Griffith MC, Ingham JM. Pullout strength of NSM CFRP strips bonded to vintage 17 clay brick masonry. Eng Struct 2014;69:25-36.

18 [6] Dizhur D, Griffith M, Ingham J. Out-of-plane strengthening of unreinforced masonry walls 19 using near surface mounted fibre reinforced polymer strips. Eng Struct 2014;59(2):330-43.

20 [7] De Lorenzis L, Nanni A. Shear Strengthening of Reinforced Concrete Beams with NearSurface Mounted Fiber-Reinforced Polymer Rods. ACI Struct J 2001;98(1):60-8.

22 [8] Sharaky IA, Torres L, Baena M, Miàs C. An experimental study of different factors 23 affecting the bond of NSM FRP bars in concrete. Compos Struct 2013;99:350-65. 
1 [9] Khshain NT, Al-Mahaidi R, Abdouka K. Bond behaviour between NSM CFRP strips and 2 concrete substrate using single-lap shear testing with epoxy adhesive. Compos Struct $3 \quad 2015 ; 132: 205-14$.

4 [10] Seracino R, Raizal Saifulnaz MR, Oehlers DJ. Generic Debonding Resistance of EB and

6 [11] Al-Saadi NTK, Mohammed A, Al-Mahaidi R. Performance of RC beams rehabilitated with

9 [12] Seo SY, Feo L, Hui D. Bond strength of near surface-mounted FRP plate for retrofit of

11 [13] Capozucca R. Analysis of bond-slip effects in RC beams strengthened with NSM CFRP

13 [14] Mohammed A, Tareq N, Al-saadi K, Al-mahaidi R. Assessment of bond strength of NSM CFRP strips embedded in concrete using cementitious adhesive made with graphene oxide. Constr Build Mater 2017;154:504-13.

[15] Zhang SS, Yu T. Effect of groove spacing on bond strength of Near-Surface Mounted ( NSM ) bonded joints with multiple FRP strips 2017;155:103-13.

[16] Turco V, Galati N, De Lorenzis L, Modena C, Nanni A. Bond between Near Surface Mounted FRP rods and masonry in structural strengthening. Adv. with Compos. plast, Ed. I, Crivelli-Visconti, Milan, Italy: 2003, p. 209-17.

[17] Konthesingha KMC, Masia MJ, Petersen RB, Page AW. Bond behaviour of NSM FRP strips to modern clay brick. 11th Candian Mason. Symp., Toronto, Ontario: 2009.

[18] Kashyap J, Willis CR, Griffith MC, Ingham JM, Masia MJ. Debonding resistance of FRP- 
2 [19] De Lorenzis L, Nanni A. Characterization of FRP rods as Near-Surface Mounted

to-clay brick masonry joints. Eng Struct 2012;41:186-98. Reinforcement. J Compos Constr 2001;5(2):114-21.

[20] Coelho MRF, Sena-Cruz JM, Neves L a. C. A review on the bond behavior of FRP NSM systems in concrete. Constr Build Mater 2015;93:1157-69.

[21] ASTM C67. Standard test methods for sampling and testing brick and structural clay tile. 2014.

[22] EN 772-1. Methods of test for masonry units. Determination of compressive strength. BSI; 2011.

[23] ASTM C39. Standard test method for compressive strength of cylindrical concrete specimens. 2016.

[24] Fernandes PMG, Silva PM, Sena-Cruz J. Bond and flexural behavior of concrete elements strengthened with NSM CFRP laminate strips under fatigue loading. Eng Struct 2015;84:350-61.

[25] Maljaee H, Ghiassi B, Lourenço PB, Oliveira DV. Moisture-induced degradation of interfacial bond in FRP-strengthened masonry. Compos Part B Eng 2016;87:47-58.

[26] Maljaee H, Ghiassi B, Lourenço PB, Oliveira DV. FRP-brick masonry bond degradation under hygrothermal conditions. Compos Struct 2016;147:143-54.

[27] Hassan TK, Rizkalla SH. Bond mechanism of Near-Surface-Mounted Fiber-Reinforced Polymer bars for flexural strengthening of concrete streuctures 2011;(101):1-7.

[28] De Lorenzis L, Rizzo A, La Tegola A. A modified pull-out test for bond of Near-Surface Mounted FRP rods in concrete. Compos Part B Eng 2002;33(8):589-603.

[29] Liu Y, Dawe J, McInerney J. Behaviour of GFRP sheets bonded to masonry walls. Proc. 
Int. Symp. Bond Behav. FRP Struct., 2005, p. 473-80.

2 [30] Willis CR, Yang Q, Seracino R, Griffith MC. Bond behaviour of FRP-to-clay brick masonry joints. Eng Struct 2009;31(11):2580-7.

4 [31] Zhang SS, Teng JG, Yu T. Bond strength model for CFRP Strips Near-Surface Mounted to concrete. J Compos Constr 2014;18(3).

6 [32] Cruz JS, Barros J. Modeling of bond between Near-Surface Mounted CFRP laminate strips and concrete. Comput Struct 2004;82(17-19):1513-21.

8 [33] Zhang SS, Teng JG, Yu T. Bond-slip model for CFRP strips near-surface mounted to $9 \quad$ concrete. Eng Struct 2013;56:945-53. 
1 List of Tables

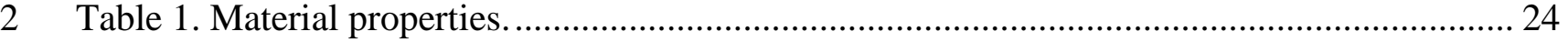

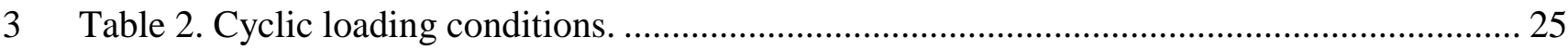

4 Table 3. Database of experimental results on NSM-to-masonry bond behavior........................... 26

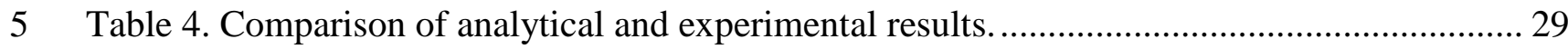

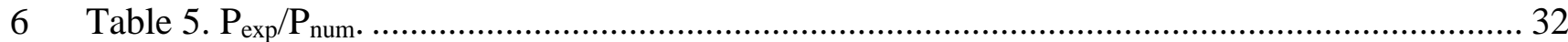

8 List of Figures

9 Fig 1. Position of tapes inside the groove.

10 Fig 2. Geometry of the test specimens and the test setup (dimensions are in $\mathrm{mm}$ ).

11 Fig 3. Test setup improvements.

12 Fig 4 . The load history of static cyclic tests.

13 Fig 5. Typical failure modes.

14 Fig 6. Load-displacement curves obtained from (a) ) Test setup 1; (b) ) Test setup 2; (c) Test

15 setup 3.

16 Fig 7. Effect of groove size on the debonding force.

17 Fig 8. Variation of failure mode in each series with bond length.

18 Fig 9. (a) Envelope of force-slip relationship and (b) variation of debonding force with bonded

19 length.

20 Fig 10. (a) Load-slip response under cyclic loading (b) in-cycle degradation trend.

21 Fig 11. Evaluation of existing bond strength models: (a) Seracino et al. [10] (b) Zhang et al. [31]

22 (c) Kashyap et al. [18] (Generic) (d) Kashyap et al. [18] (NSM) and (e) Willis et al. [31].

23 Fig 12. The best fitted curve for the predicted effective bond length.

24 Fig 13. Accuracy of proposed model.

25

26 
1 Table 1. Material properties.

\begin{tabular}{llll}
\hline & Compressive strength & Tensile strength & Elastic modulus \\
& $(\mathrm{MPa})$ & $(\mathrm{MPa})$ & $(\mathrm{GPa})$ \\
\hline Masonry brick & 14.5 & 1.6 & - \\
Epoxy adhesive & - & 22.0 & 7.2 \\
CFRP laminate & - & - & 165.0 \\
\hline
\end{tabular}

2 
1 Table 2. Cyclic loading conditions.

\begin{tabular}{lllll}
\hline Specimen & $\begin{array}{l}\text { Number of cycles } \\
\text { in each interval }\end{array}$ & $\begin{array}{l}\text { First cycle } \\
(\mathrm{mm})\end{array}$ & $\begin{array}{l}\text { Displacement levels } \\
(\mathrm{mm})\end{array}$ & $\begin{array}{l}\text { Failure at } \\
\text { cycle }\end{array}$ \\
\hline 1 & 3 & 4 & $4-5-6-7-8$ & 14 \\
2 & 3 & 4 & $4-5-6-7-7.5-8$ & 16 \\
3 & 3 & 5 & $5-6-7-8$ & 10 \\
\hline
\end{tabular}

2 
1 Table 3. Database of experimental results on NSM-to-masonry bond behavior.

\begin{tabular}{|c|c|c|c|c|c|c|c|c|c|c|c|}
\hline \multirow[t]{2}{*}{ Reference } & \multirow[t]{2}{*}{ ID } & \multirow[t]{2}{*}{ Specimen } & \multicolumn{3}{|l|}{ FRP } & \multicolumn{2}{|c|}{ Groove size } & \multirow{2}{*}{$\begin{array}{l}\mathrm{L}_{\mathrm{b}} \\
(\mathrm{mm})\end{array}$} & \multirow{2}{*}{$\begin{array}{l}\mathrm{f}_{\mathrm{ut}} \\
(\mathrm{MPa})\end{array}$} & \multirow[t]{2}{*}{$\varphi_{\mathrm{f}}$} & \multirow[t]{2}{*}{$\mathrm{L}_{\mathrm{per}}$} \\
\hline & & & ఏ્छ & ఏ్ఏ & $\underbrace{\overparen{\sigma}}_{\text {U] }}$ & 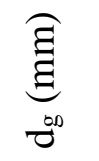 & 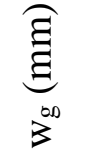 & & & & \\
\hline & 1 & E-10-SS & 6.35 & 6.3 & 40.8 & 7.35 & 8.35 & 254 & 1.93 & 0.88 & 23.05 \\
\hline & 2 & E-15-SS & 6.35 & 6.3 & 40.8 & 7.35 & 8.35 & 381 & 1.93 & 0.88 & 23.05 \\
\hline & 3 & $1 \mathrm{~A}$ & 2.80 & 15 & 207 & 16 & 4.80 & 355 & 3.57 & 3.33 & 36.80 \\
\hline & 4 & $2 \mathrm{~A}$ & 2.80 & 15 & 207 & 16 & 4.80 & 355 & 3.57 & 3.33 & 36.80 \\
\hline & 5 & $2 \mathrm{~B}$ & 2.80 & 15 & 207 & 16 & 4.80 & 355 & 3.57 & 3.33 & 36.80 \\
\hline & 6 & $2 \mathrm{C}$ & 2.80 & 15 & 207 & 16 & 4.80 & 355 & 3.57 & 3.33 & 36.80 \\
\hline & 7 & S1-A & 2.80 & 15 & 207 & 16 & 4.80 & 336 & 3.57 & 3.33 & 36.80 \\
\hline & 8 & S1-B-NG & 2.80 & 15 & 207 & 16 & 4.80 & 336 & 3.57 & 3.33 & 36.80 \\
\hline & 9 & S1-C-SG & 2.80 & 15 & 207 & 16 & 4.80 & 336 & 3.57 & 3.33 & 36.80 \\
\hline & 10 & M-SG-3.6-10 & 3.60 & 10 & 165 & 11 & 5.60 & 420 & 3.41 & 1.96 & 27.60 \\
\hline & 11 & M-NSG-4.2-10 & 4.20 & 10 & 165 & 11 & 6.20 & 420 & 3.41 & 1.77 & 28.20 \\
\hline & 12 & M-NSG-7.2-10 & 7.20 & 10 & 165 & 11 & 9.20 & 420 & 3.41 & 1.20 & 31.20 \\
\hline & 13 & M-NSG-4.8-7.5 & 4.80 & 7.5 & 165 & 8.5 & 6.80 & 420 & 3.41 & 1.25 & 23.80 \\
\hline & 14 & M-NSG-4.8-5 & 4.80 & 5 & 165 & 6 & 6.80 & 420 & 3.41 & 0.88 & 18.80 \\
\hline & 15 & St1.0-3-10-1/2 & 1.20 & 10 & 162 & 11 & 3.20 & 244 & 3.55 & 3.44 & 25.20 \\
\hline & 16 & St1.0-3-15-1/2 & 1.20 & 15 & 162 & 16 & 3.20 & 241 & 3.55 & 5.00 & 35.20 \\
\hline & 17 & HO1.5-4-15-1/4 & 1.20 & 15 & 162 & 16 & 3.20 & 328 & 3.55 & 5.00 & 35.20 \\
\hline & 18 & HO1.5-4-15-1/4-N & 1.20 & 15 & 162 & 16 & 3.20 & 334 & 3.55 & 5.00 & 35.20 \\
\hline & 19 & HO1.0-4-15-0 & 1.20 & 15 & 162 & 16 & 3.20 & 328 & 3.55 & 5.00 & 35.20 \\
\hline & 20 & HO1.0-4-15-0-N & 1.20 & 15 & 162 & 16 & 3.20 & 334 & 3.55 & 5.00 & 35.20 \\
\hline & 21 & St1.0-4-15-1/2 & 1.20 & 15 & 162 & 16 & 3.20 & 328 & 3.55 & 5.00 & 35.20 \\
\hline & 22 & HO1.5-4-15-1/6 & 1.20 & 15 & 162 & 16 & 3.20 & 328 & 3.55 & 5.00 & 35.20 \\
\hline & 23 & HO1.5-4-15-1/4 & 1.20 & 15 & 162 & 16 & 3.20 & 328 & 3.55 & 5.00 & 35.20 \\
\hline & 24 & HO1.5-4-20-1/2 & 1.20 & 20 & 162 & 21 & 3.20 & 328 & 3.55 & 6.56 & 45.20 \\
\hline & 25 & St1.0-4-20-AC & 1.20 & 20 & 162 & 20 & 3.20 & 328 & 3.55 & 6.25 & 43.20 \\
\hline & 26 & St1.0-4-20-BC & 1.20 & 20 & 162 & 21 & 3.20 & 328 & 3.55 & 6.56 & 45.20 \\
\hline & 27 & A1-4-15-(6/20) & 1.20 & 15 & 155 & 20 & 6.0 & 320 & 3.80 & 3.33 & 46.00 \\
\hline & 28 & A2-4-15-(6/20) & 1.20 & 15 & 155 & 20 & 6.0 & 315 & 3.80 & 3.33 & 46.00 \\
\hline & 29 & A3-4-15-(6/20) & 1.20 & 15 & 155 & 20 & 6.0 & 325 & 3.80 & 3.33 & 46.00 \\
\hline & 30 & A4-4-152-(6/20) & 2.40 & 15 & 155 & 20 & 6.0 & 310 & 3.80 & 3.33 & 46.00 \\
\hline & 31 & A5-4-152-(6/20) & 2.40 & 15 & 155 & 20 & 6.0 & 315 & 3.80 & 3.33 & 46.00 \\
\hline & 32 & B1-4-15-(6/20) & 1.20 & 15 & 155 & 20 & 6.0 & 560 & 2.60 & 3.33 & 46.00 \\
\hline & 33 & B2-4-15-(7/20) & 1.20 & 15 & 155 & 20 & 7.0 & 340 & 2.60 & 2.86 & 47.00 \\
\hline & 34 & B4-4-15-(3/20) & 1.20 & 15 & 155 & 20 & 3.0 & 350 & 2.60 & 6.67 & 43.00 \\
\hline & 35 & B6-4-15-(12/20) & 1.20 & 15 & 155 & 20 & 12.0 & 350 & 2.60 & 1.67 & 52.00 \\
\hline & 36 & B7-4-10-(6/15) & 1.20 & 10 & 155 & 15 & 6.0 & 350 & 2.60 & 2.50 & 36.00 \\
\hline & 37 & B8-4-10-(6/15) & 1.20 & 10 & 155 & 15 & 6.0 & 360 & 2.60 & 2.50 & 36.00 \\
\hline & 38 & B9-4-20-(7/25) & 1.20 & 20 & 155 & 25 & 7.0 & 380 & 2.60 & 3.57 & 57.00 \\
\hline
\end{tabular}




\begin{tabular}{|c|c|c|c|c|c|c|c|c|c|c|}
\hline 39 & B10-4-25-(6/30) & 1.20 & 25 & 155 & 30 & 6.0 & 360 & 2.60 & 5.00 & 66.00 \\
\hline 40 & B13-4-15-(6/30) & 1.20 & 15 & 155 & 30 & 6.0 & 360 & 2.60 & 5.00 & 66.00 \\
\hline 41 & B14-4-15-(6/35) & 1.20 & 15 & 155 & 35 & 6.0 & 450 & 2.60 & 5.83 & 76.00 \\
\hline 42 & B15-4-152-(7/20) & 2.40 & 15 & 155 & 20 & 7.0 & 350 & 2.60 & 2.86 & 47.00 \\
\hline 43 & B16-5-15-(6/20) & 1.20 & 15 & 155 & 20 & 6.0 & 360 & 2.60 & 3.33 & 46.00 \\
\hline 44 & B17-4-15-(6/25) & 1.20 & 15 & 155 & 25 & 6.0 & 265 & 2.60 & 4.17 & 56.00 \\
\hline 45 & B18-4-30-(6/35) & 1.20 & 30 & 155 & 35 & 6.0 & 260 & 2.60 & 5.83 & 76.00 \\
\hline 46 & B19-3-15-(6/20) & 1.20 & 15 & 155 & 20 & 6.0 & 180 & 2.60 & 3.33 & 46.00 \\
\hline 47 & B20-3-30-(6/20) & 1.20 & 10 & 155 & 20 & 6.0 & 180 & 2.60 & 3.33 & 46.00 \\
\hline 48 & B21-2-15-(6/20) & 1.20 & 15 & 155 & 20 & 6.0 & 310 & 2.60 & 3.33 & 46.00 \\
\hline 49 & B22-1-20-(6/20) & 1.20 & 20 & 155 & 20 & 6.0 & 310 & 2.60 & 3.33 & 46.00 \\
\hline 50 & $C 2-4-25-(6 / 30)$ & 1.20 & 25 & 155 & 30 & 6.0 & 310 & 3.40 & 5.00 & 66.00 \\
\hline 51 & C5-4-15-(6/20 & 1.20 & 15 & 155 & 20 & 6.0 & 310 & 3.40 & 3.33 & 46.00 \\
\hline 52 & C6-4-152-(6/20) & 1.20 & 15 & 155 & 20 & 6.0 & 310 & 3.40 & 3.33 & 46.00 \\
\hline 53 & D2-4-15-(7/20) & 1.20 & 15 & 155 & 20 & 7.0 & 350 & 2.50 & 2.86 & 47.00 \\
\hline 54 & E1-4-15-(6/20 & 2.40 & 15 & 155 & 20 & 6.0 & 330 & 1.90 & 3.33 & 46.00 \\
\hline 55 & F1-4-15-(6/20) & 1.20 & 15 & 155 & 20 & 6.0 & 330 & 1.20 & 3.33 & 46.00 \\
\hline 56 & F2-4-15-(6/20) & 1.20 & 15 & 155 & 20 & 6.0 & 330 & 1.20 & 3.33 & 46.00 \\
\hline 57 & C2G3B30_1 & 1.40 & 10 & 165 & 13 & 3.0 & 30 & 1.60 & 4.33 & 29.00 \\
\hline 58 & C2G3B30_2 & 1.40 & 10 & 165 & 13 & 3.0 & 30 & 1.60 & 4.33 & 29.00 \\
\hline 59 & C2G3B30_3 & 1.40 & 10 & 165 & 13 & 3.0 & 30 & 1.60 & 4.33 & 29.00 \\
\hline 60 & C2G3B60_1 & 1.40 & 10 & 165 & 13 & 3.0 & 60 & 1.60 & 4.33 & 29.00 \\
\hline 61 & C2G3B60_2 & 1.40 & 10 & 165 & 13 & 3.0 & 60 & 1.60 & 4.33 & 29.00 \\
\hline 62 & C2G3B60_3 & 1.40 & 10 & 165 & 13 & 3.0 & 60 & 1.60 & 4.33 & 29.00 \\
\hline 63 & C2G3B90_1 & 1.40 & 10 & 165 & 13 & 3.0 & 90 & 1.60 & 4.33 & 29.00 \\
\hline 64 & C2G3B90_2 & 1.40 & 10 & 165 & 13 & 3.0 & 90 & 1.60 & 4.33 & 29.00 \\
\hline 65 & C2G3B90_3 & 1.40 & 10 & 165 & 13 & 3.0 & 90 & 1.60 & 4.33 & 29.00 \\
\hline 66 & C3G5B30_1 & 1.40 & 10 & 165 & 16 & 5.4 & 30 & 1.60 & 3.00 & 37.80 \\
\hline 67 & C3G5B30_2 & 1.40 & 10 & 165 & 16 & 5.4 & 30 & 1.60 & 3.00 & 37.80 \\
\hline 68 & C3G5B30_4 & 1.40 & 10 & 165 & 15 & 5.3 & 30 & 1.60 & 2.91 & 36.10 \\
\hline 69 & C3G5B30_5 & 1.40 & 10 & 165 & 16.3 & 5.4 & 30 & 1.60 & 3.02 & 38.00 \\
\hline 70 & C3G5B60_1 & 1.40 & 10 & 165 & 14.7 & 5.3 & 60 & 1.60 & 2.77 & 34.70 \\
\hline 71 & C3G5B60_2 & 1.40 & 10 & 165 & 15.7 & 5.3 & 60 & 1.60 & 2.96 & 36.70 \\
\hline 72 & C3G5B60_3 & 1.40 & 10 & 165 & 16.7 & 5.2 & 60 & 1.60 & 3.21 & 38.60 \\
\hline 73 & C3G5B60_4 & 1.40 & 10 & 165 & 15.3 & 5.3 & 60 & 1.60 & 2.89 & 35.90 \\
\hline 74 & C3G5B60_5 & 1.40 & 10 & 165 & 16.1 & 5.4 & 60 & 1.60 & 2.98 & 37.60 \\
\hline 75 & C3G5B90_1 & 1.40 & 10 & 165 & 15.5 & 5.3 & 90 & 1.60 & 2.92 & 36.30 \\
\hline 76 & C3G5B90_2 & 1.40 & 10 & 165 & 15.8 & 5.4 & 90 & 1.60 & 2.93 & 37.00 \\
\hline 77 & C3G5B90_3 & 1.40 & 10 & 165 & 15.2 & 5.2 & 90 & 1.60 & 2.92 & 35.60 \\
\hline 78 & C3G5B90_4 & 1.40 & 10 & 165 & 15.2 & 5.2 & 90 & 1.60 & 2.92 & 35.60 \\
\hline 79 & C3G5B90_5 & 1.40 & 10 & 165 & 16.4 & 5.3 & 90 & 1.60 & 3.09 & 38.10 \\
\hline 80 & C3G5B120_1 & 1.40 & 10 & 165 & 16.3 & 5.3 & 120 & 1.60 & 3.08 & 37.90 \\
\hline 81 & C3G5B120_2 & 1.40 & 10 & 165 & 15.5 & 5.4 & 120 & 1.60 & 2.87 & 36.40 \\
\hline 82 & C3G5B120_3 & 1.40 & 10 & 165 & 15.6 & 5.3 & 120 & 1.60 & 2.94 & 36.50 \\
\hline 83 & C3G5B120_4 & 1.40 & 10 & 165 & 15.5 & 5.3 & 120 & 1.60 & 2.92 & 36.30 \\
\hline
\end{tabular}




\begin{tabular}{lllllllllll}
\hline 84 & C3G5B120_5 & 1.40 & 10 & 165 & 15.5 & 5.3 & 120 & 1.60 & 2.92 & 36.30 \\
85 & C3G5B150_1 & 1.40 & 10 & 165 & 15.7 & 5.6 & 150 & 1.60 & 2.80 & 37.00 \\
86 & C3G5B150_2 & 1.40 & 10 & 165 & 16.0 & 5.4 & 150 & 1.60 & 2.96 & 37.40 \\
87 & C3G5B150_4 & 1.40 & 10 & 165 & 16.2 & 5.3 & 150 & 1.60 & 3.06 & 37.70 \\
89 & C3G5B150_5 & 1.40 & 10 & 165 & 15.8 & 5.3 & 150 & 1.60 & 2.98 & 36.90 \\
\hline
\end{tabular}

1 
1 Table 4. Comparison of analytical and experimental results.

\begin{tabular}{|c|c|c|c|c|c|c|c|c|c|c|c|c|}
\hline \multirow[b]{2}{*}{$\Theta$} & \multirow[b]{2}{*}{ 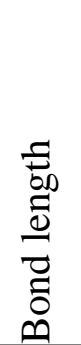 } & \multicolumn{3}{|c|}{ Effective bond length } & \multicolumn{2}{|c|}{ Willis et al. } & \multicolumn{2}{|c|}{$\begin{array}{l}\text { Kahsyap et } \\
\text { al. } \\
\text { (Generic) }\end{array}$} & \multicolumn{2}{|c|}{$\begin{array}{l}\text { Kahsyap et } \\
\text { al. (NSM) }\end{array}$} & \multicolumn{2}{|c|}{ Proposed } \\
\hline & & 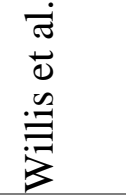 & 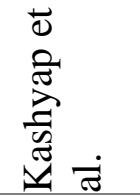 & $\begin{array}{l}\text { Dू. } \\
0 \\
0 \\
0 \\
0 \\
0\end{array}$ & 害 & 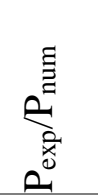 & 害 & 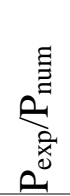 & 气 & 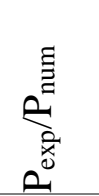 & 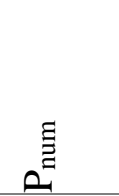 & 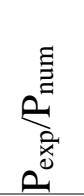 \\
\hline 1 & 254 & 212.0 & 112.56 & 155.9 & 12.81 & 1.50 & 16.29 & 1.1 & 22.40 & 0.86 & 11.93 & 1.61 \\
\hline 2 & 381 & 212.0 & 112.56 & 155.9 & 12.81 & 1.45 & 16.29 & 1.1 & 22.40 & 0.83 & 11.93 & 1.55 \\
\hline 3 & 355 & 310.3 & 255.02 & 215.2 & 76.39 & 0.81 & 81.37 & 0.7 & 74.05 & 0.83 & 67.17 & 0.92 \\
\hline 4 & 355 & 310.3 & 255.02 & 215.2 & 76.39 & 0.85 & 81.37 & 0.8 & 74.05 & 0.88 & 67.17 & 0.97 \\
\hline 5 & 355 & 310.3 & 255.02 & 215.2 & 76.39 & 0.83 & 81.37 & 0.7 & 74.05 & 0.86 & 67.17 & 0.95 \\
\hline 6 & 355 & 310.3 & 255.02 & 215.2 & 76.39 & 0.87 & 81.37 & 0.8 & 74.05 & 0.90 & 67.17 & 0.99 \\
\hline 7 & 336 & 310.3 & 255.02 & 215.2 & 76.39 & 1.03 & 81.37 & 0.9 & 74.05 & 1.06 & 67.17 & 1.17 \\
\hline 8 & 336 & 310.3 & 255.02 & 215.2 & 76.39 & 0.85 & 81.37 & 0.8 & 74.05 & 0.88 & 67.17 & 0.97 \\
\hline 9 & 336 & 310.3 & 255.02 & 215.2 & 76.39 & 0.95 & 81.37 & 0.8 & 74.05 & 0.98 & 67.17 & 1.08 \\
\hline 10 & 420 & 294.5 & 235.37 & 203.2 & 46.29 & 1.40 & 51.56 & 1.2 & 55.27 & 1.18 & 41. & 1.55 \\
\hline 11 & 420 & 311.3 & 250.49 & 215.5 & 49.20 & 1.14 & 55.21 & 1.0 & 61.09 & 0.92 & 44. & 1.26 \\
\hline 12 & 420 & 366.9 & 306.92 & 260.7 & 61.08 & 1.10 & 70.55 & 0.9 & 88.21 & 0.76 & 56. & 1.19 \\
\hline 13 & 420 & 299.1 & 248.93 & 211.7 & 38.17 & 1.56 & 43.94 & 1.3 & 54.19 & 1.10 & 35. & 1.68 \\
\hline 14 & 420 & 259.0 & 225.52 & 189.6 & 25.27 & 1.77 & 29.84 & 1.5 & 41.00 & 1.09 & 23.79 & 1.88 \\
\hline 15 & 244 & 178.0 & 145.68 & 123.7 & 30.03 & 0.92 & 31.94 & 0.8 & 28.79 & 0.96 & 26. & 1.05 \\
\hline 16 & 241 & 182.7 & 153.25 & 131.7 & 47.97 & 0.98 & 49.65 & 0.9 & 39.84 & 1.17 & 41.30 & 1.13 \\
\hline 17 & 8 & & & & & 0 . & & & & & & 07 \\
\hline 18 & 334 & 182.7 & 153.25 & 131.7 & 47.97 & 1.06 & 49.65 & 1.0 & 39.84 & 1.27 & 41. & 1.23 \\
\hline 19 & 328 & 182.7 & 153.25 & & 47.97 & 0.80 & 49.65 & 0.7 & 39.84 & 6 & 41 & 93 \\
\hline 20 & 334 & 182.7 & 153.25 & 131.7 & 47.97 & 0.97 & 49.65 & 0.9 & 39.84 & 1.17 & 41. & 1.13 \\
\hline 21 & 328 & 182.7 & 153.25 & 131.7 & 47.97 & 0.87 & 49.65 & 0.8 & 39.84 & 1.04 & 41.30 & 1.00 \\
\hline 22 & 328 & 182.7 & 153.25 & 131.7 & 47.97 & 0.87 & 49.65 & 0.8 & 39.84 & 1.05 & 41. & 1.01 \\
\hline 23 & 328 & 182.7 & 153.25 & 131.7 & 47.97 & 0.80 & 49.65 & 0.7 & 39.84 & 0.96 & 41.30 & 0.93 \\
\hline 24 & 328 & 181.5 & 157.86 & 136.9 & 67.43 & 0.73 & 68.41 & 0.7 & 50.46 & 0.98 & 57. & 0.86 \\
\hline 25 & 328 & 186.7 & 161.16 & 139.5 & 65.08 & 0.77 & 66.26 & 0.7 & 49.62 & 1.01 & 55.38 & 0.90 \\
\hline 26 & 328 & 181.5 & 157.86 & 136.9 & 67.43 & 0.76 & 68.41 & 0.7 & 50.46 & 1.01 & 57.23 & 0.89 \\
\hline 27 & 320 & 151.4 & 131.41 & 105.0 & 50.23 & 0.74 & 53.07 & 0.7 & 48.29 & 0.77 & 44.22 & 0.84 \\
\hline 28 & 315 & 151.4 & 131.41 & 105.0 & 50.23 & 0.99 & 53.07 & 0.9 & 48.29 & 1.03 & 44.22 & 1.12 \\
\hline 29 & 325 & 151.4 & 131.41 & 105.0 & 50.23 & 1.01 & 53.07 & 0.9 & 48.29 & 1.05 & 44.22 & 1.14 \\
\hline 30 & 310 & 214.2 & 185.84 & 148.5 & 71.03 & 0.85 & 75.06 & 0.8 & 68.30 & 0.89 & 62.54 & 0.97 \\
\hline 31 & 315 & 214.2 & 185.84 & 148.5 & 71.03 & 0.92 & 75.06 & 0.8 & 68.30 & 0.95 & 62.54 & 1.04 \\
\hline 32 & 560 & 190.2 & 118.61 & 132.2 & 40.00 & 1.18 & 44.40 & 1.0 & 40.40 & 1.17 & 34.96 & 1.35 \\
\hline 33 & 340 & 187.2 & 116.62 & 129.3 & 38.83 & 1.03 & 43.59 & 0.9 & 41.60 & 0.96 & 34.21 & 1.17 \\
\hline 34 & 350 & 189.6 & 126.13 & 143.8 & 46.41 & 0.76 & 48.97 & 0.7 & 35.95 & 0.98 & 39.13 & 0.90 \\
\hline 35 & 350 & 169.8 & 108.51 & 118.2 & 35.44 & 1.01 & 41.39 & 0.8 & 46.68 & 0.76 & 32.11 & 1.11 \\
\hline 36 & 350 & 173.3 & 108.22 & 119.5 & 26.79 & 0.87 & 30.37 & 0.7 & 30.21 & 0.77 & 23.77 & 0.98 \\
\hline
\end{tabular}




\begin{tabular}{|c|c|c|c|c|c|c|c|c|c|c|c|c|}
\hline 37 & 360 & 173.3 & 108.22 & 119.5 & 26.79 & 0.99 & 30.37 & 0.8 & 30.21 & 0.88 & 23.77 & 1.12 \\
\hline 38 & 380 & 197.4 & 123.38 & 137.8 & 52.36 & 0.80 & 57.83 & 0.7 & 51.51 & 0.81 & 45.60 & 0.92 \\
\hline 39 & 360 & 203.2 & 129.93 & 146.7 & 68.81 & 0.72 & 74.16 & 0.6 & 59.51 & 0.84 & 58.89 & 0.85 \\
\hline 40 & 360 & 157.4 & 100.64 & 113.7 & 53.30 & 0.62 & 57.45 & 0.5 & 46.10 & 0.71 & 45.62 & 0.72 \\
\hline 41 & 450 & 144.8 & 94.37 & 107.1 & 59.57 & 0.60 & 63.48 & 0.5 & 48.56 & 0.73 & 50.57 & 0.70 \\
\hline 42 & 350 & 264.8 & 164.93 & 182.9 & 54.91 & 0.97 & 61.64 & 0.8 & 58.84 & 0.91 & 48.38 & 1.10 \\
\hline 43 & 360 & 190.2 & 118.61 & 132.2 & 40.00 & 0.86 & 44.40 & 0.7 & 40.40 & 0.85 & 34.96 & 0.99 \\
\hline 44 & 265 & 172.2 & 108.46 & 121.8 & 46.80 & 0.53 & 51.11 & 0.4 & 43.40 & 0.57 & 40.44 & 0.62 \\
\hline 45 & 260 & 204.8 & 133.46 & 151.5 & 84.24 & 0.53 & 89.77 & 0.5 & 68.68 & 0.65 & 71.52 & 0.63 \\
\hline 46 & 180 & 190.2 & 118.61 & 132.2 & 37.85 & 1.02 & 44.40 & 0.8 & 40.40 & 0.96 & 34.96 & 1.10 \\
\hline 47 & 80 & 155.3 & 96.85 & 107.9 & 16.82 & 1.50 & 29.95 & 0.8 & 27.25 & 0.92 & 28.60 & 0.88 \\
\hline 48 & 310 & 190.2 & 118.61 & 132.2 & 40.00 & 0.87 & 44.40 & 0.7 & 40.40 & 0.86 & 34.96 & 1.00 \\
\hline 49 & 310 & 219.6 & 136.96 & 152.6 & 46.19 & 0.39 & 51.27 & 0.3 & 46.65 & 0.38 & 40.37 & 0.44 \\
\hline 50 & 310 & 172.9 & 139.69 & 124.7 & 80.83 & 0.75 & 84.13 & 0.7 & 67.51 & 0.89 & 69.53 & 0.87 \\
\hline 51 & 310 & 161.9 & 127.52 & 112.3 & 46.98 & 0.92 & 50.37 & 0.8 & 45.83 & 0.94 & 41.28 & 1.05 \\
\hline 52 & 310 & 161.9 & 127.52 & 112.3 & 46.98 & 1.03 & 50.37 & 0.9 & 45.83 & 1.06 & 41.28 & 1.17 \\
\hline 53 & 350 & 191.7 & 115.39 & 132.4 & 37.92 & 0.90 & 42.79 & 0.8 & 40.84 & 0.83 & 33.39 & 1.02 \\
\hline 54 & 330 & 324.7 & 154.12 & 226.2 & 46.86 & 0.61 & 54.19 & 0.5 & 49.31 & 0.58 & 40.72 & 0.70 \\
\hline 55 & 330 & 302.4 & 96.26 & 211.4 & 25.15 & 0.83 & 30.87 & 0.6 & 28.09 & 0.74 & 21.66 & 0.96 \\
\hline 56 & 330 & 302.4 & 96.26 & 211.4 & 25.15 & 0.78 & 30.87 & 0.6 & 28.09 & 0.70 & 21.66 & 0.91 \\
\hline 57 & 30 & 291.1 & 120.49 & 207.3 & 2.38 & 4.32 & 6.68 & 1.5 & 5.61 & 1.84 & 6.19 & 1.67 \\
\hline 58 & 30 & 291.1 & 120.49 & 207.3 & 2.38 & 4.65 & 6.68 & 1.6 & 5.61 & 1.98 & 6.19 & 1.79 \\
\hline 59 & 30 & 291.1 & 120.49 & 207.3 & 2.38 & 4.88 & 6.68 & 1.7 & 5.61 & 2.08 & 6.19 & 1.88 \\
\hline 60 & 60 & 291.1 & 120.49 & 207.3 & 4.77 & 2.56 & 13.37 & 0.9 & 11.21 & 1.09 & 11.25 & 1.09 \\
\hline 61 & 60 & .1 & 120.49 & 20 & 4.77 & 3.36 & 13.37 & 1.2 & 11.21 & 1.43 & 11.25 & 1.42 \\
\hline 62 & 60 & 291.1 & 120.49 & 207.3 & 4.77 & 2.90 & 13.37 & 1.0 & 11.21 & 1.23 & 11.25 & 1.23 \\
\hline 63 & 90 & 291.1 & 120.49 & 207.3 & 7.15 & 1.96 & 20.05 & 0.7 & 16.82 & 0.83 & 15.18 & 0.92 \\
\hline 64 & 90 & 291.1 & 120.49 & 207.3 & 7.15 & 2.14 & 20.05 & 0.7 & 16.82 & 0.91 & 15.18 & 1.01 \\
\hline 65 & 90 & 291.1 & 120.49 & 207.3 & 7.15 & 2.41 & 20.05 & 0.8 & 16.82 & 1.02 & 15.18 & 1.13 \\
\hline 66 & 30 & 254.7 & 103.99 & 176.8 & 2.82 & 3.08 & 8.24 & 1.0 & 7.75 & 1.12 & 7.54 & 1.15 \\
\hline 67 & 30 & 254.7 & 103.99 & 176.8 & 2.82 & 3.54 & 8.24 & 1.2 & 7.75 & 1.29 & 7.54 & 1.33 \\
\hline 68 & 30 & 260.3 & 106.28 & 180.5 & 2.68 & 3.18 & 7.84 & 1.0 & 7.44 & 1.15 & 7.19 & 1.19 \\
\hline 69 & 30 & 254.1 & 103.74 & 176.4 & 2.84 & 3.78 & 8.29 & 1.3 & 7.78 & 1.38 & 7.59 & 1.42 \\
\hline 70 & 60 & 264.9 & 108.20 & 183.5 & 5.10 & 2.85 & 14.96 & 0.9 & 14.41 & 1.01 & 12.32 & 1.18 \\
\hline 71 & 60 & 258.4 & 105.49 & 179.3 & 5.47 & 2.62 & 15.98 & 0.9 & 15.08 & 0.95 & 13.08 & 1.09 \\
\hline 72 & 60 & 252.6 & 103.19 & 175.8 & 5.86 & 2.57 & 17.01 & 0.8 & 15.66 & 0.96 & 13.85 & 1.09 \\
\hline 73 & 60 & 261.0 & 106.55 & 180.9 & 5.32 & 2.86 & 15.57 & 0.9 & 14.81 & 1.03 & 12.78 & 1.19 \\
\hline 74 & 60 & 255.3 & 104.24 & 177.2 & 5.61 & 2.13 & 16.38 & 0.7 & 15.43 & 0.77 & 13.38 & 0.89 \\
\hline 75 & 90 & 259.7 & 106.01 & 180.1 & 8.09 & 2.32 & 23.66 & 0.7 & 22.42 & 0.84 & 17.09 & 1.10 \\
\hline 76 & 90 & 257.2 & 105.01 & 178.4 & 8.25 & 2.04 & 24.12 & 0.7 & 22.85 & 0.74 & 17.35 & 0.97 \\
\hline 77 & 90 & 262.2 & 107.05 & 181.8 & 7.93 & 2.47 & 23.20 & 0.8 & 21.99 & 0.89 & 16.83 & 1.16 \\
\hline 78 & 90 & 262.2 & 107.05 & 181.8 & 7.93 & 2.26 & 23.20 & 0.7 & 21.99 & 0.81 & 16.83 & 1.06 \\
\hline 79 & 90 & 254.0 & 103.71 & 176.5 & 8.60 & 1.82 & 25.04 & 0.6 & 23.32 & 0.67 & 17.93 & 0.87 \\
\hline 80 & 120 & 254.6 & 103.96 & 176.9 & 11.39 & 1.68 & 28.75 & 0.6 & 26.82 & 0.71 & 20.50 & 0.93 \\
\hline 81 & 120 & 259.1 & 105.79 & 179.6 & 10.77 & 1.90 & 27.81 & 0.7 & 26.50 & 0.77 & 19.69 & 1.04 \\
\hline
\end{tabular}




\begin{tabular}{lllllllllllll}
\hline 82 & 120 & 259.0 & 105.75 & 179.7 & 10.86 & 1.97 & 27.98 & 0.7 & 26.46 & 0.81 & 19.81 & 1.08 \\
\hline 83 & 120 & 259.7 & 106.01 & 180.1 & 10.79 & 1.99 & 27.87 & 0.7 & 26.41 & 0.81 & 19.72 & 1.09 \\
\hline 84 & 120 & 259.7 & 106.01 & 180.1 & 10.79 & 1.69 & 27.87 & 0.6 & 26.41 & 0.69 & 19.72 & 0.93 \\
\hline 85 & 150 & 256.7 & 104.83 & 177.8 & 13.62 & 1.57 & 27.91 & 0.7 & 26.80 & 0.80 & 20.84 & 1.03 \\
\hline 86 & 150 & 255.9 & 104.50 & 177.6 & 13.93 & 1.54 & 28.36 & 0.7 & 26.76 & 0.80 & 21.20 & 1.01 \\
\hline 87 & 150 & 255.2 & 104.21 & 177.3 & 14.14 & 1.45 & 28.64 & 0.7 & 26.77 & 0.76 & 21.42 & 0.96 \\
\hline 89 & 150 & 257.7 & 105.23 & 178.9 & 13.76 & 1.40 & 28.20 & 0.6 & 26.56 & 0.73 & 21.07 & 0.92 \\
\hline
\end{tabular}


1 Table 5. $\mathrm{P}_{\text {exp }} / \mathrm{P}_{\text {num. }}$.

\begin{tabular}{lllll} 
model & mean & $\max$ & $\min$ & $\mathrm{CoV}(\%)$ \\
\hline Proposed & 1.08 & 1.88 & 0.44 & 23 \\
Willis et al. [30] & 1.52 & 4.88 & 0.39 & 64 \\
Kashyap et al. (Generic) [18] & 0.87 & 1.74 & 0.35 & 28 \\
Kashyap et al. (NSM) [18] & 0.95 & 2.08 & 0.38 & 27 \\
Seracino et al. [10] & 0.51 & 1.44 & 0.14 & 54 \\
Zhange et al. [31] & 0.31 & 0.52 & 0.14 & 24
\end{tabular}

2 


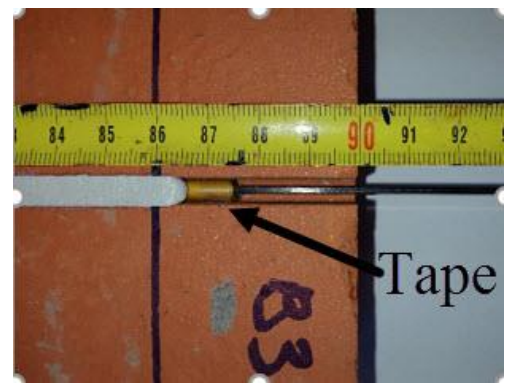

Fig 1. Position of tapes inside the groove. 

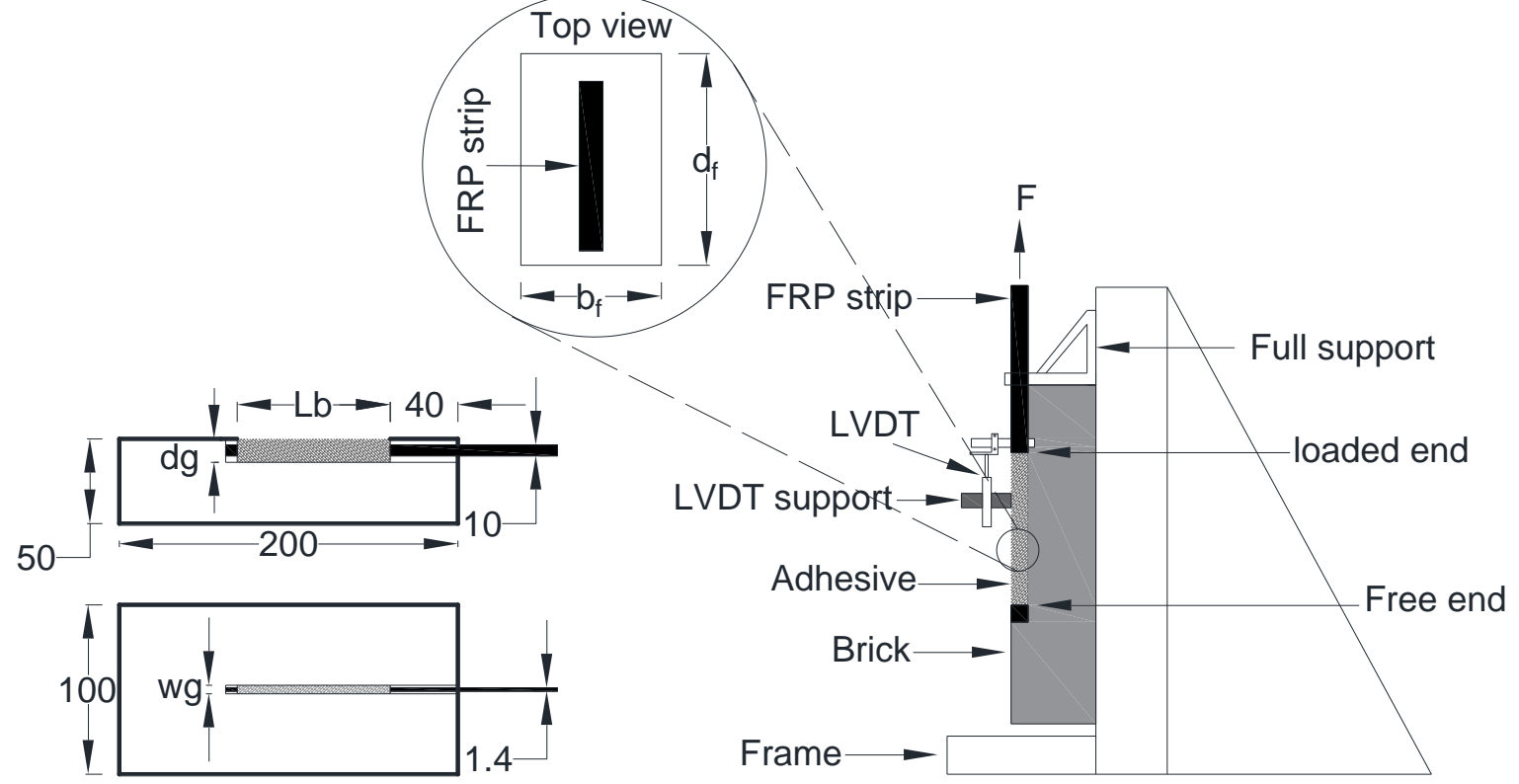

Fig 2. Geometry of the test specimens and the test setup (dimensions are in $\mathrm{mm}$ ). 


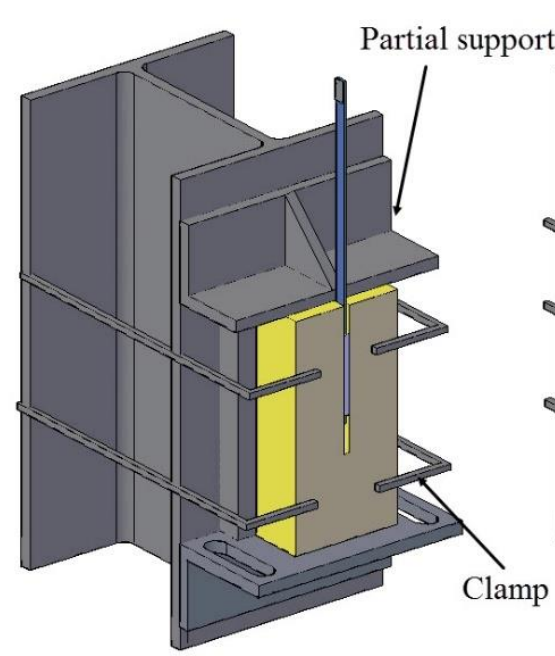

Class 1

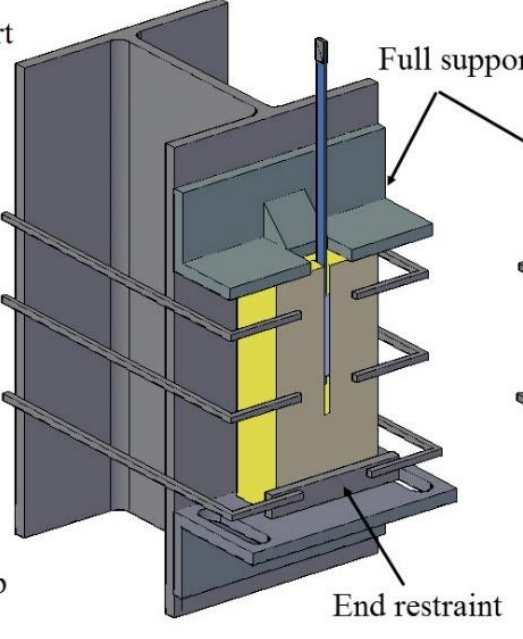

Class 2

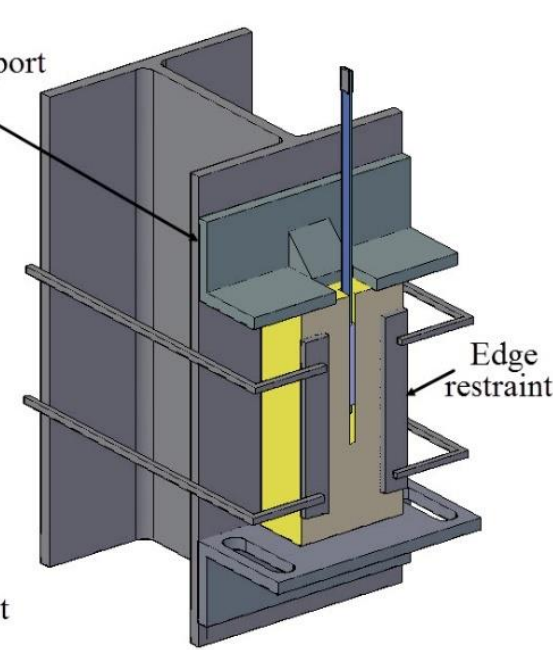

Class 3

Fig 3. Test setup improvements. 

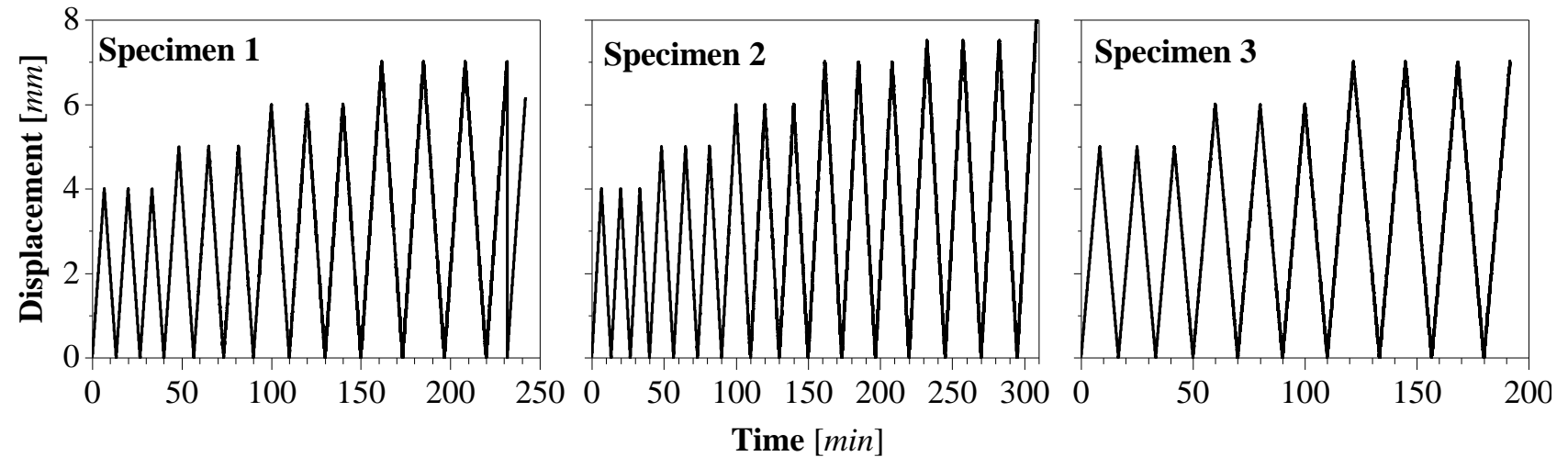

Fig 4 . The load history of static cyclic tests.

3 

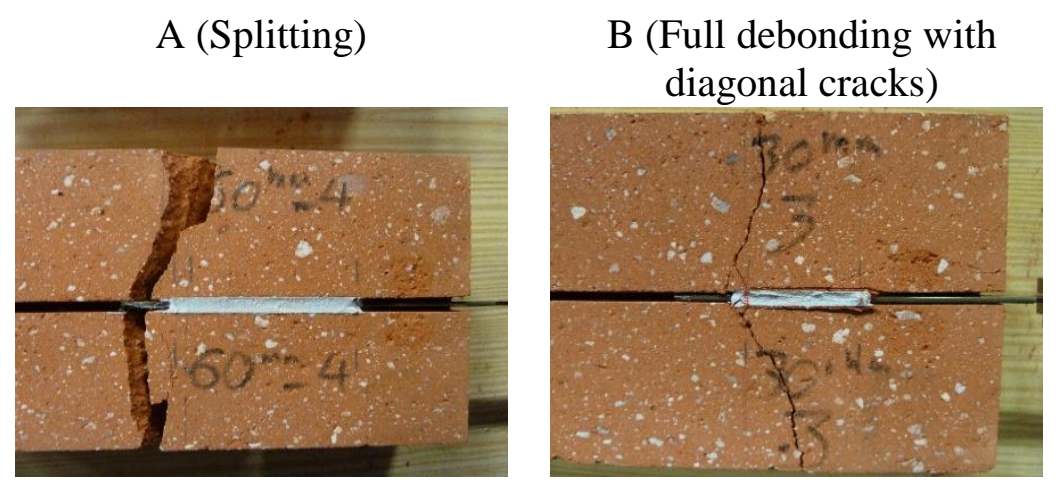

C (Interface)

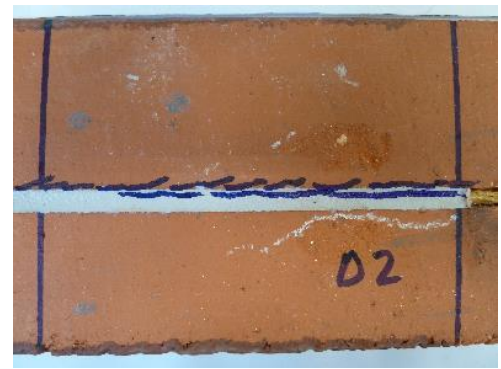

Fig 5. Typical failure modes. 


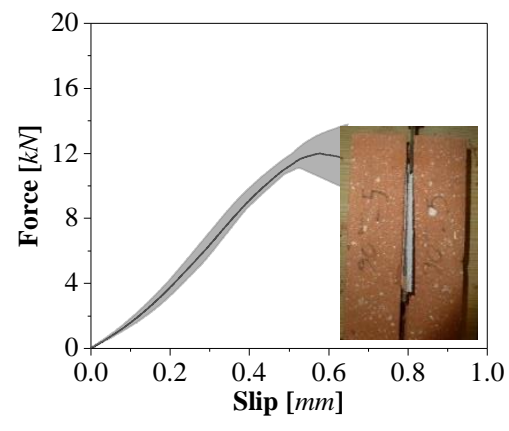

(a)

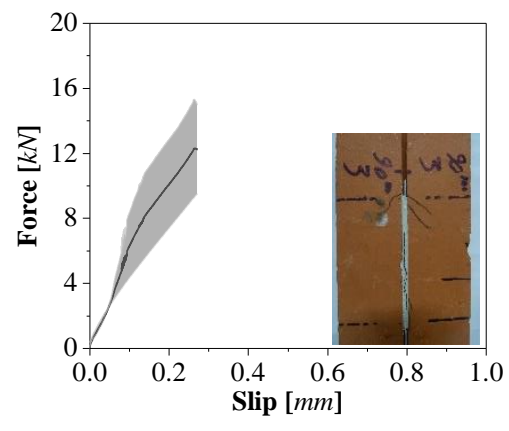

(b)

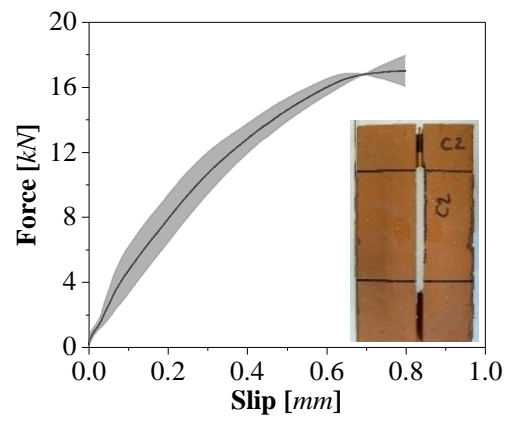

(c)

2 Fig 6. Load-displacement curves obtained from (a) Test setup 1; (b) Test setup 2; (c) Test setup 3 3. 


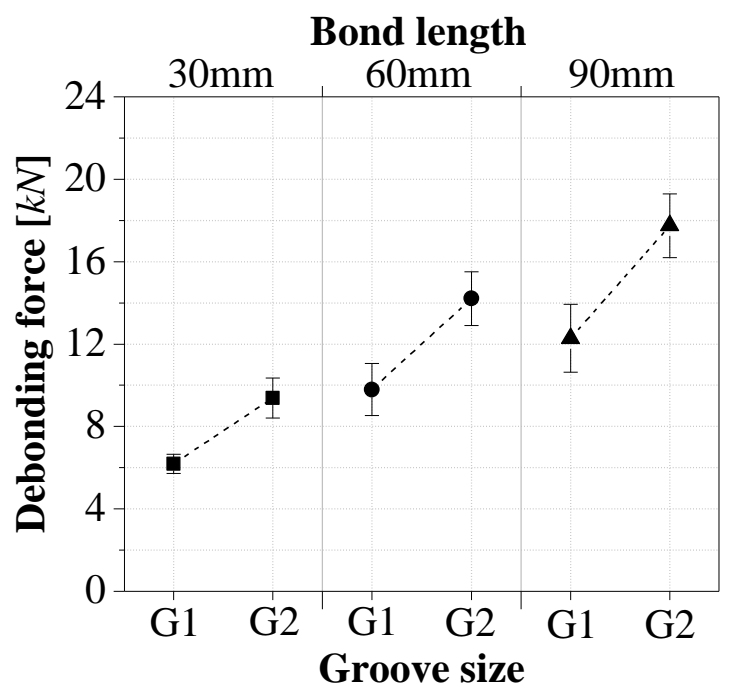

Fig 7. Effect of groove size on the debonding force. 


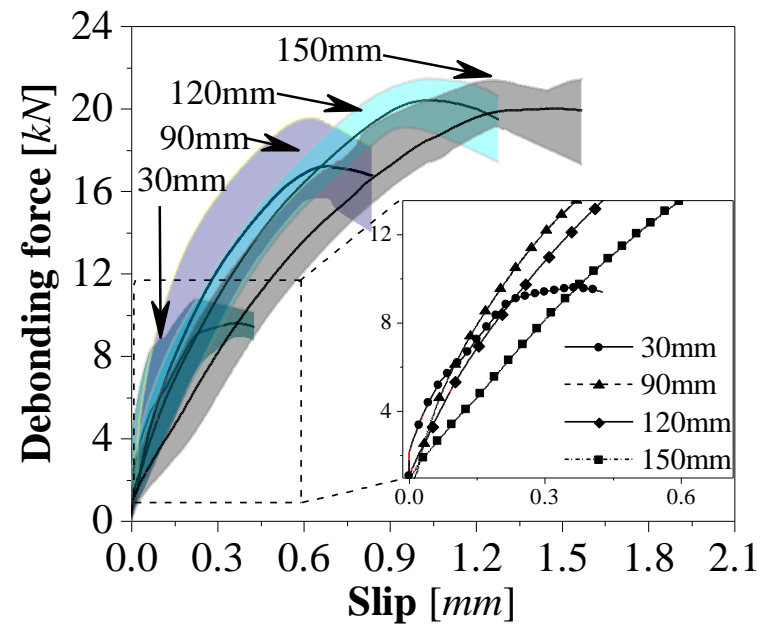

(a)

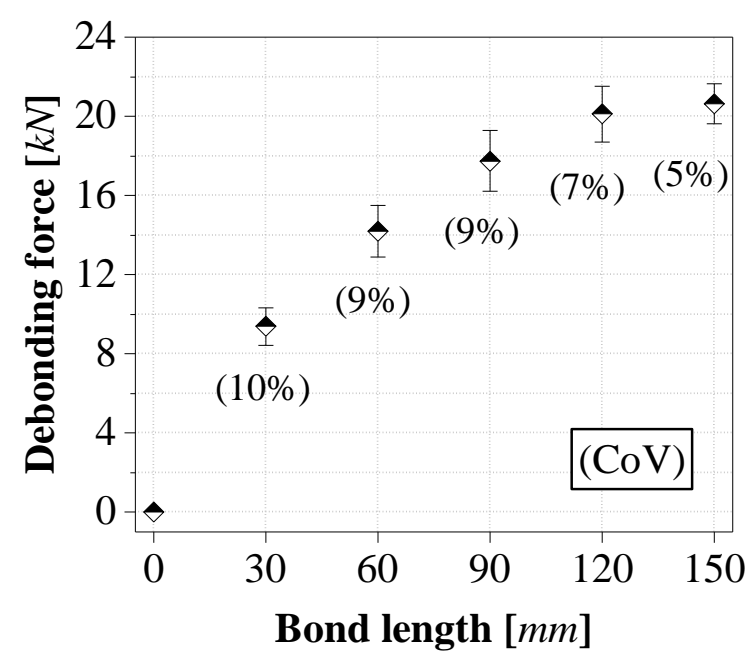

(b)

Fig 8. (a) Envelope of force-slip relationship and (b) variation of debonding force with bonded length. 


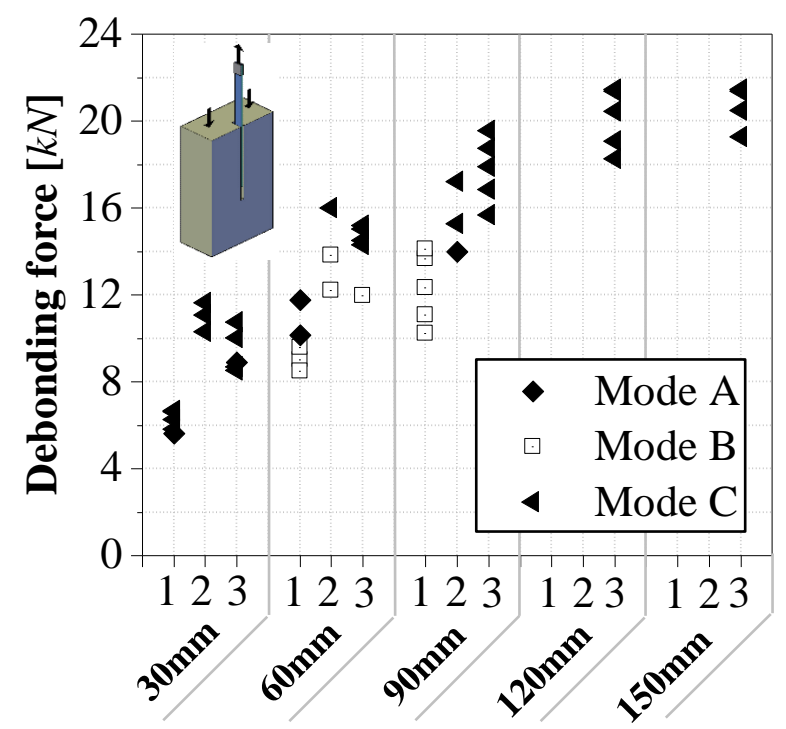

Fig 9. Variation of failure mode in each series with bond length.

3 


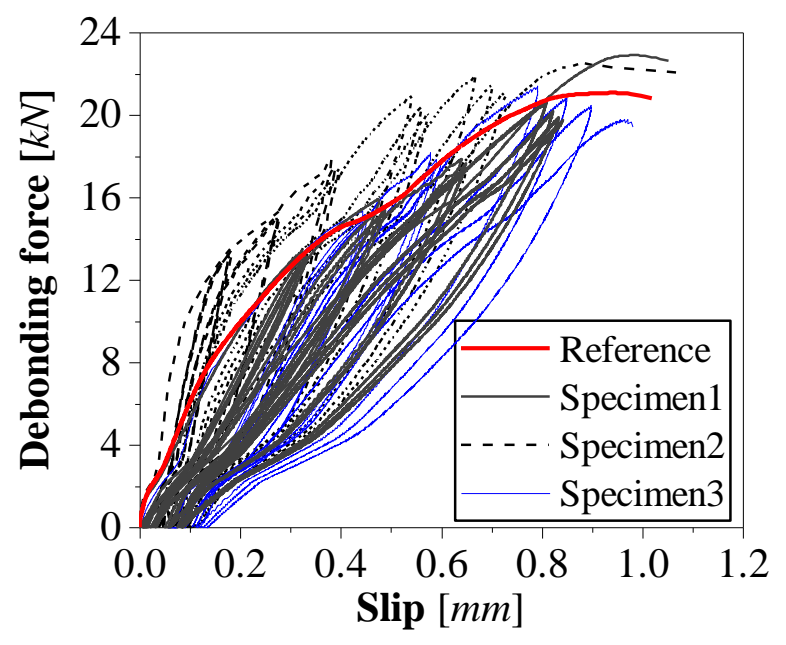

(a)

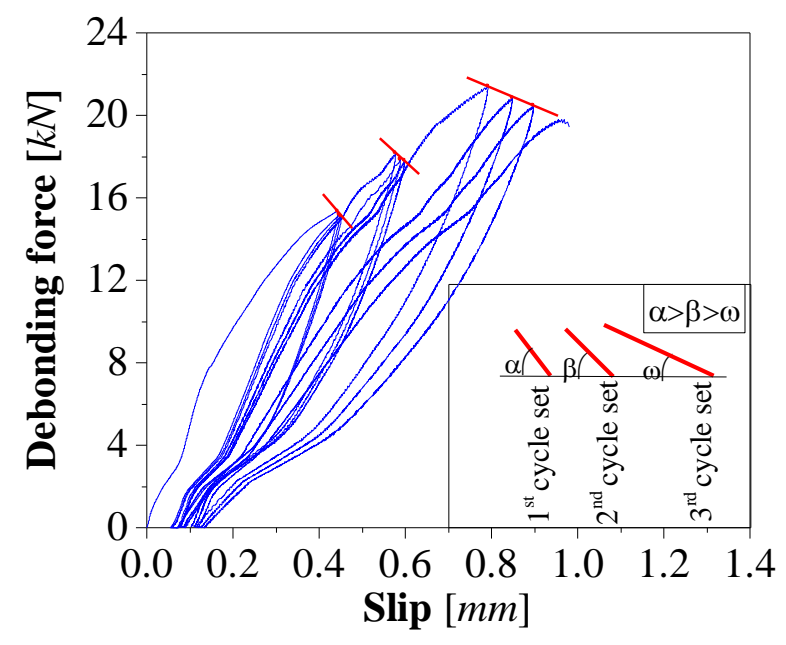

(b)

Fig 10. (a) Load-slip response under cyclic loading (b) in-cycle degradation trend. 


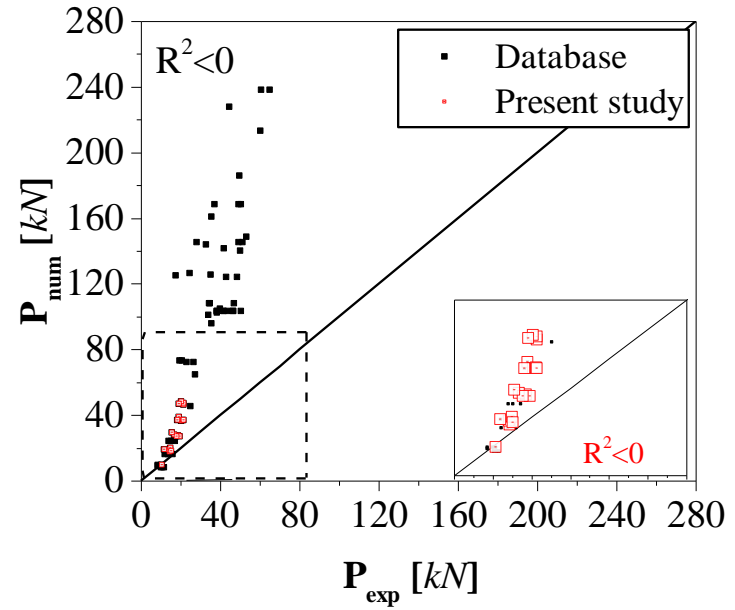

(a)

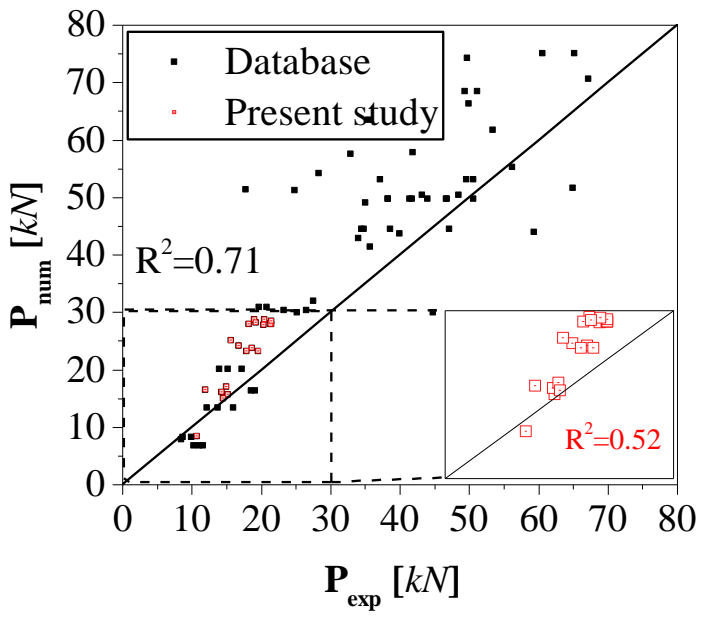

(c)

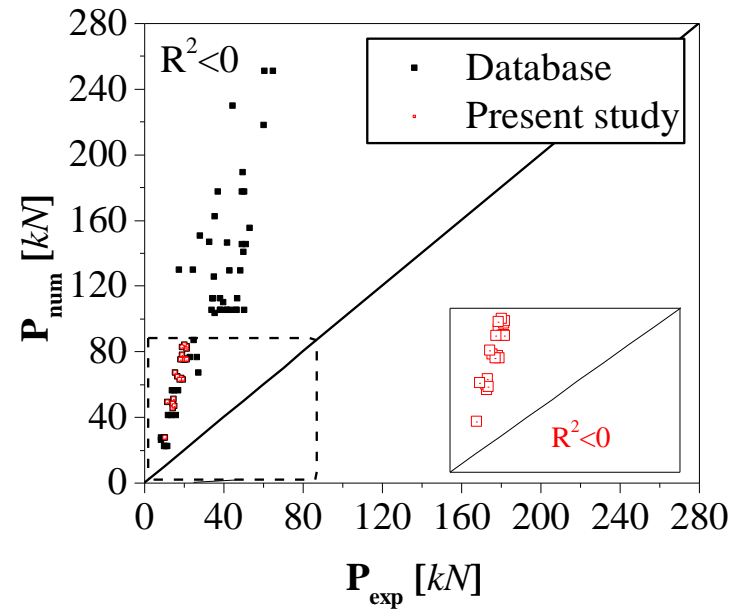

(b)

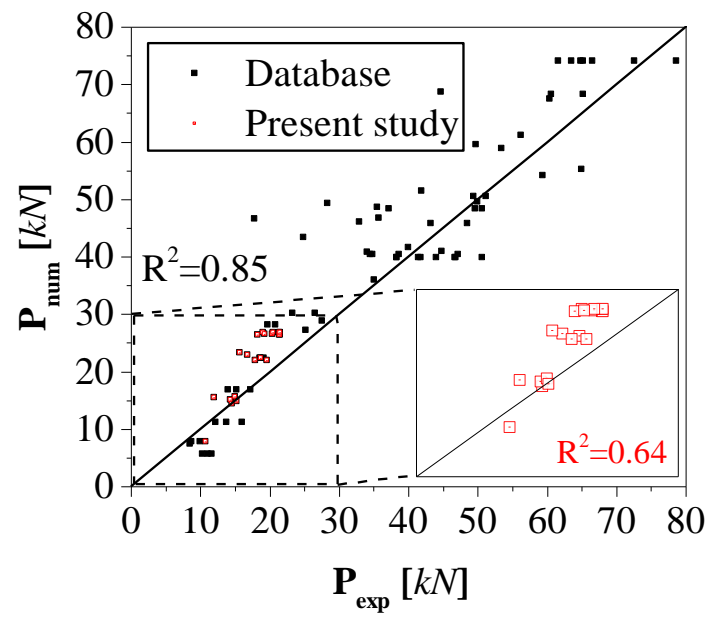

(d)

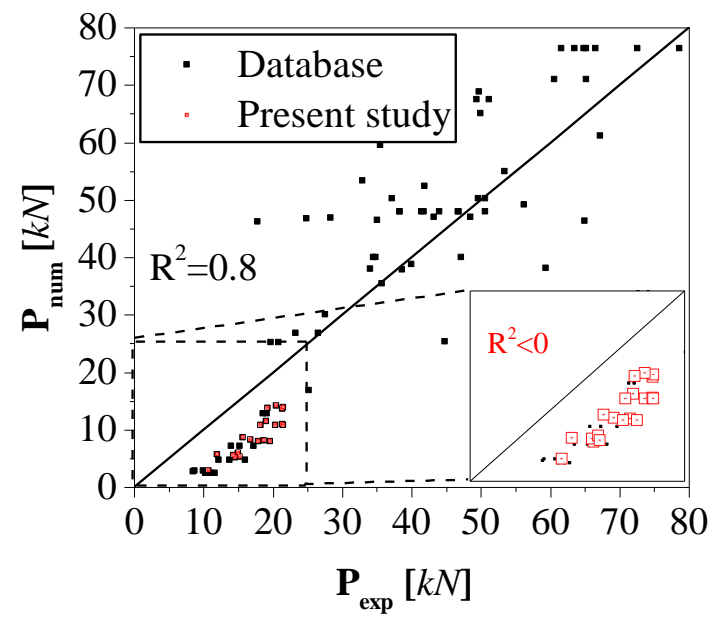

(e)

1 Fig 11. Evaluation of existing bond strength models: (a) Seracino et al. [10] (b) Zhang et al. [31]

2 (c) Kashyap et al. [18] (Generic) (d) Kashyap et al. [18] (NSM) and (e) Willis et al. [31]. 


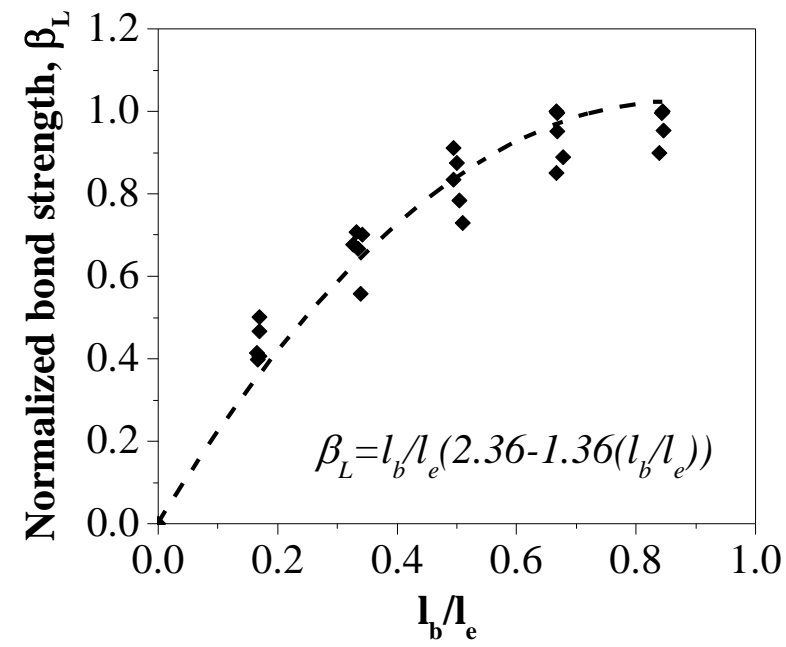

Fig 12. The best fitted curve for the predicted effective bond length. 


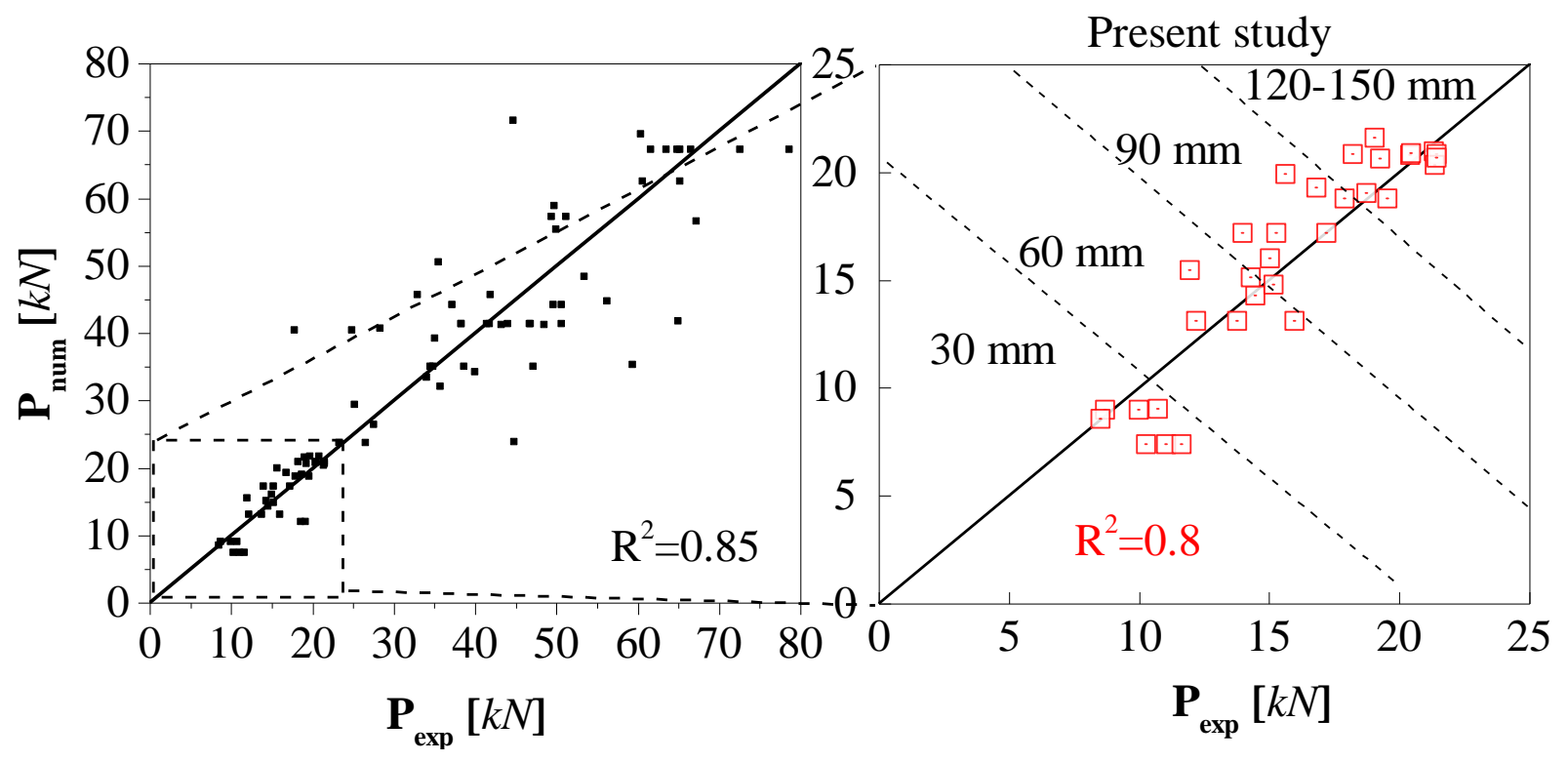

Fig 13. Accuracy of proposed model. 